\title{
Fracture of the Mandibular Condyle
}

\author{
Vikas Dhupar
}

\subsection{Introduction}

Maxillofacial surgeons commonly come across a high incidence of condylar fractures in their practice. A French surgeon [1] in the eighteenth century described a high propensity for a narrow portion in the subcondylar region to fracture, which is a common occurrence even today. In spite of a common occurrence, the management has been controversial as there is no established consensus in the treatment of condylar fractures. Traditionally closed reduction has been the treatment of choice for condylar fractures and have been treated by various forms of intermaxillary fixation. With the improvement in radiographic imaging and biomaterials used in the fixation, surgical management has gradually found acceptance as it restores early function.

\subsection{Surgical Anatomy}

The mandibular condyle forms a part of the temporomandibular joint which is unique (Box 53.1), and it is made of the following structures:

- Condyle of the mandible

- Squamous portion of the temporal bone

- Articular disc (contained within the TMJ)

- Ligaments
Box 53.1. TMJ-Unique Characteristics

- It is a ginglymoarthrodial joint, having both a hinge and a gliding action

- It has an end point closure

- It has a fibrocartilage disc

\subsubsection{Condyle}

The condyle is one of the two processes of the mandible present on the superior portion of the ramus. The condylar head is ovoid in shape measuring approximately $15-20 \mathrm{~mm}$ mediolaterally and $8-10 \mathrm{~mm}$ anteroposteriorly in dimension [2]. The mandibular condyle articulates with the glenoid fossa present in the squamous portion of the temporal bone to form the temporomandibular joint (Fig. 53.1). Squamous portion of the temporal bone is as thin as $2 \mathrm{~mm}$ as a result; the condylar processes maybe driven into the middle cranial fossa following trauma.

\subsubsection{Articular Disc}

The squamous portion of the temporal bone and the condyle is separated by a dense fibrous connective tissue called the articular disc. The disc is firmly anchored to the condyle by the medial and lateral collateral ligaments, and it merges with the capsule in the periphery. The joint space is divided into superior and inferior compartments by the disc.

\subsubsection{Capsule and Ligaments}

The capsule surrounds the TMJ and is reinforced by the medial and lateral ligaments which connect the mandible to the temporal bone. The synovial membrane lines the capsule. 


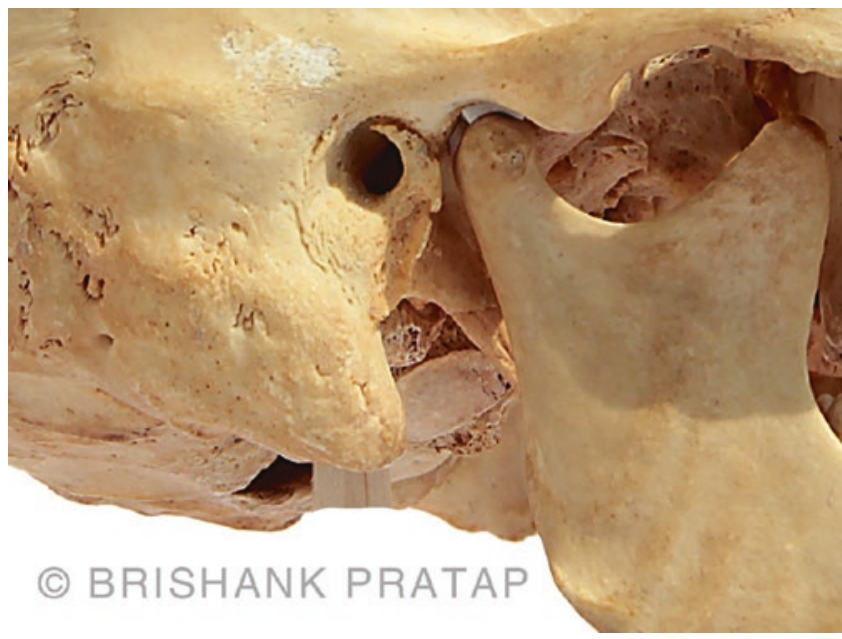

CAssociation of Oral and Maxillofacial Surgeons of India

Fig. 53.1 Bony structures of TMJ

This membrane produces synovial fluid which aids in the lubrication and nourishment of the joint. The lateral ligament also known as temporomandibular ligament has a horizontal and an oblique component which stabilizes the joint. The strength of the lateral ligament may be partly responsible for the fracture at the neck of condyle just below the insertion of the ligament [3]. The medial and lateral discal ligaments which are present inside the capsule are also called collateral ligaments. These ligaments connect the disc to the poles of the condyle. In addition to these ligaments, there are two non-capsular ligaments, namely, sphenomandibular and stylomandibular which may have a limited function.

\subsubsection{Muscles of Mastication}

There are four muscles of mastication, namely, the medial and lateral pterygoid, masseter, and the temporalis. Lateral pterygoid is attached to the pterygoid fovea at the condylar neck and is responsible for the displacement of the condylar fractures. Change in the direction of resultant forces post fracture will alter the function of the mandible during various excursion movements.

\subsubsection{Vascularisation}

The arterial blood supply to the TMJ is derived from the two terminal branches of the external carotid artery, namely:

- Superficial temporal artery

- Maxillary artery
It may be noted that the condyle receives blood supply from three sources

1. Medullary bone supplied by inferior alveolar artery

2. Overlying periosteum of the condyle

3. Attachment of lateral pterygoid muscle

This may explain the reason for the fractured condyle to remains viable even after stripping of the periosteum during the surgical procedure as the lateral pterygoid muscle remains attached to the fractured fragment [4]. The venous drainage starts in the retrodiscal plexus which drains into the superficial temporal and maxillary veins that join to form the retromandibular vein, which in turn drains into the external jugular vein.

\subsubsection{Innervation}

It is imperative to understand the innervation of the joint so as to minimize the complications following fracture of the mandible and its management. Both the sensory and motor innervation is encountered while approaching the joint. The sensory nerves are auriculotemporal, masseteric, and posterior deep temporal. Auriculotemporal nerve crosses the condyle medial to it and lies in contact with the condylar neck and capsule [5]. It is encountered in the preauricular incision and may result in postoperative complications.

\subsubsection{Facial Nerve}

It is the key nerve that transverses the face, and it is liable for the motor function of the muscles of facial expression. This nerve transverses the temporoparietal fascia and finally divides into five terminal branches in the parotid gland (Fig. 53.2). Hence all the extraoral approaches for the condylar fractures are designed keeping the facial nerve in mind. Al-Kayat and Bramley [6] found the nerve was at an average distance of $20 \mathrm{~mm}$ with a range of 8-35 $\mathrm{mm}$ from the anterior margin of the auditory canal. This is the reason the preauricular incision is given in the skin crease near the tragus or placed endurally. The neck of the condyle can be exposed via the transparotid approach. In this approach the condyle is reached through the space between the temporozygomatic and buccocervical trunks of the nerve. This results in a direct and safe approach to the neck of the condyle. The marginal mandibular nerve is encountered in the submandibular or periangular approach. This branch may further subdivide into two or more branches [7]. As a rule, the submandibular incision is given $2 \mathrm{~cm}$ below the lower border of the mandible to prevent paresis of the lower lip. 


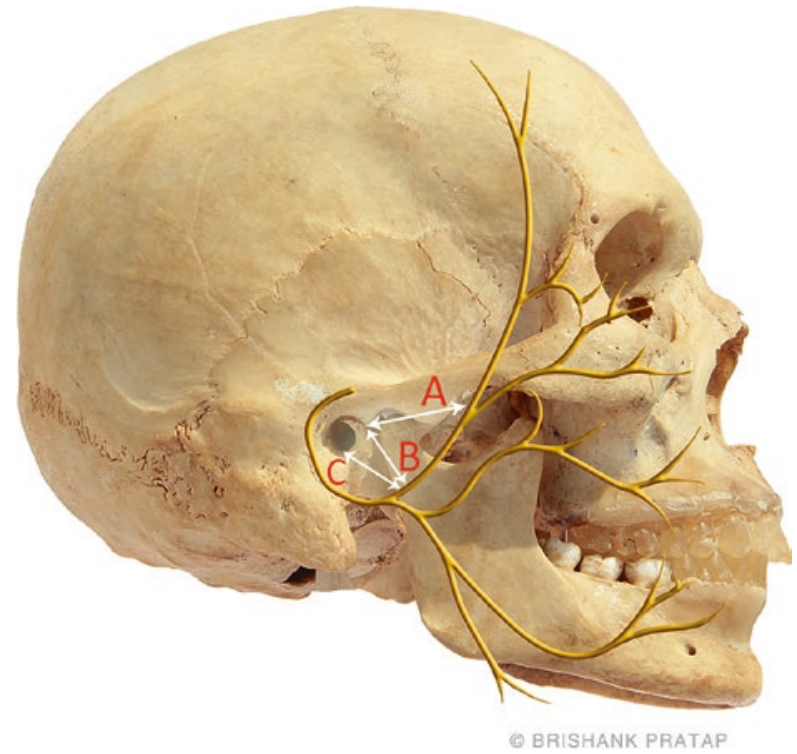

CAssociation of Oral and Maxillofacial Surgeons of India

Fig. 53.2 Terminal branches of facial nerve with Al Kayat and Bramely's [6] measurements for trunk of facial nerve. (A) $.8-3.5 \mathrm{~cm}$, (B) $2.4-3.5 \mathrm{~cm},(\mathrm{C}) 1.3 \mathrm{~cm}$

\subsection{Biomechanics of Condylar Fracture}

U-shaped mandible supports the condyles on either side. There are two major movements while opening the mouth, rotational, and translational which occur in the inferior and superior compartments, respectively. Mandibular function is characterised as a class III lever with the joint being the fulcrum [8]. The musculature applies the force between the joint and the masticatory load (Fig. 53.3).

\subsubsection{Mechanism of Injury}

Trauma causing condylar fracture was explained by Lindahl [9]. It is important to understand the pattern as it gives the type of injury sustained (Fig. 53.4).

1. Kinetic energy derived from the momentum created by the subject falling on a static object. This is an axial force which is transmitted to the condyle from the lower border of the mandible. Fracture can occur at the site of injury and at the condyles at a higher level. Occluding teeth cannot reduce the force. May also result in fracture of teeth.

2. Kinetic energy derived from the momentum created by a moving object against a static subject. Generally noted in assaults or sport injuries. More or less horizontal forces will result in a fracture both at the site of impact and at the

\section{CLASS III LEVER}

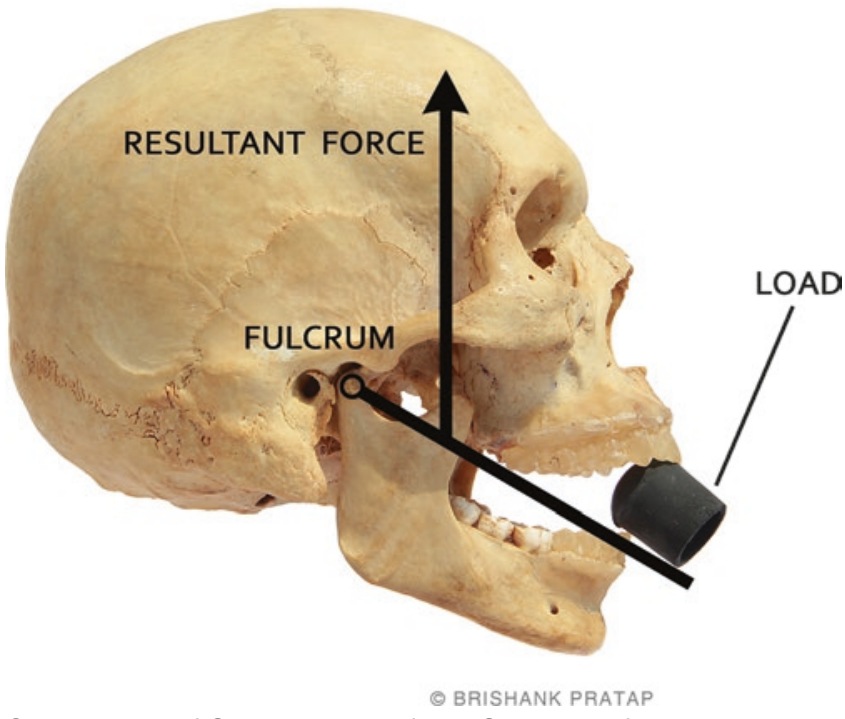

CAssociation of Oral and Maxillofacial Surgeons of India

Fig. 53.3 Function of mandible as class III lever

condyle on the opposite side. Fracture is usually at the base of the condyle.

3. Combination of the above two is seen in a road traffic accident and may result in more severe injuries.

An external force applied generally gets distributed over the entire mandible. However these forces result in the fracture of the subcondylar region which is weak and are subject to tensile stresses. A counter-coup injury is often noted in the condylar region. This prevents displacement of the condyles into the middle cranial fossa especially in bilateral fractures resulting from injuries over the chin.

\subsubsection{Effect of Condylar Fracture}

The signs and symptoms seen following trauma are due to the functional loss resulting from the disruption of the local anatomy. Following trauma a protective mechanism is triggered. It is generally expected that due to premature contact on the fractured side, excessive forces would be generated during loading of the non-fractured site on mastication. However, it is noted there is a shift of mean force vector towards the non-fractured site which results in protecting the fractured site during biting [10]. This results in neuromuscular adaptation. An increase in the muscle activity on the nonfractured side and a decrease of active force on the opposite 

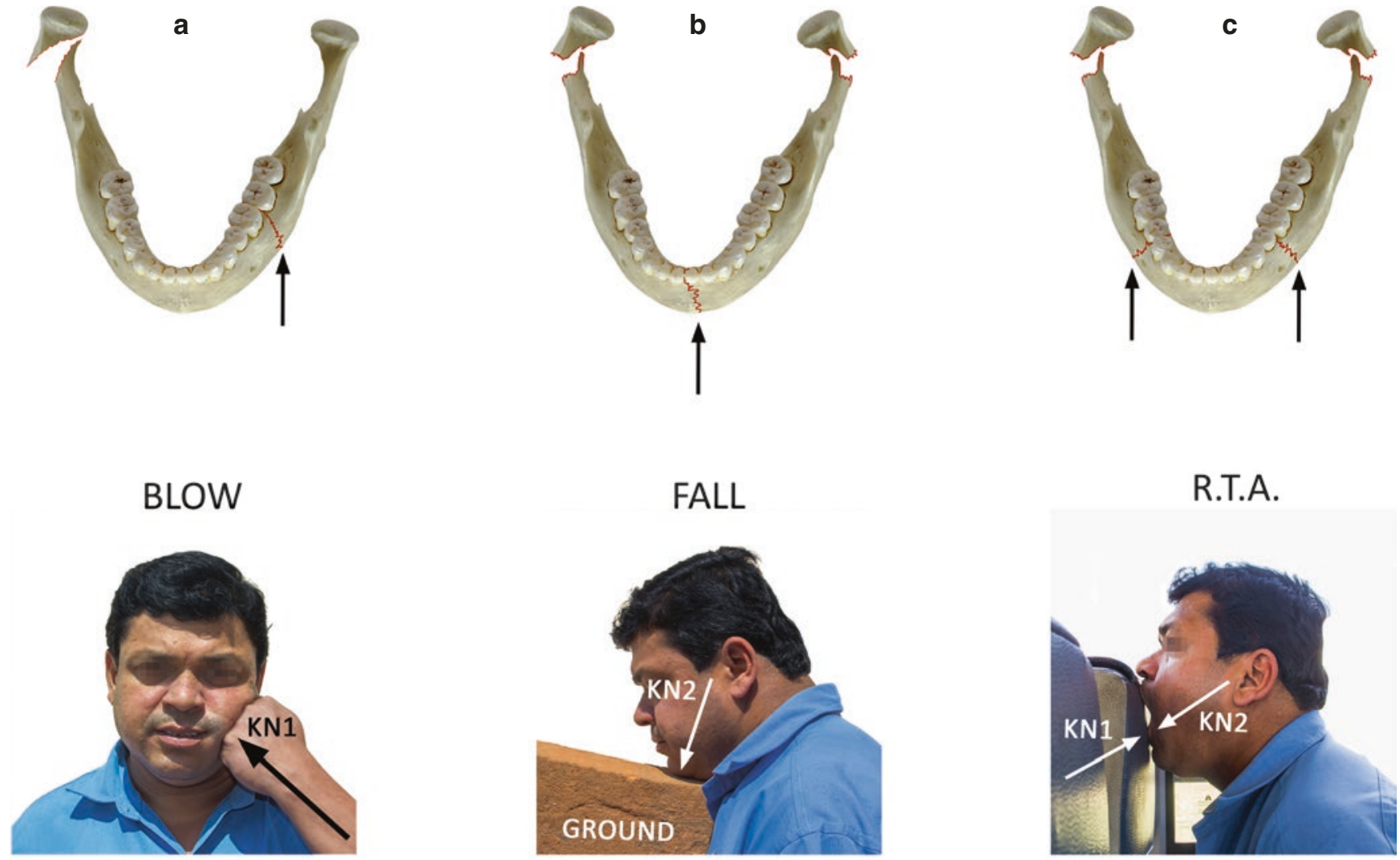

KN1 = Kinetic energy imparted to the individual.

KN2 = Kinetic energy derived from the individual.

CAssociation of Oral and Maxillofacial Surgeons of India

Fig. 53.4 Mechanism of fracture of condyle

side results in this process. Hence most of the masticatory forces are directed towards the non-fractured site and resulting in less neuromuscular adaptation on the fractured site. Refer to the article by Ellis et al. [8] for a comprehensive understanding of the biological considerations of fractures of mandibular condyle.

\subsubsection{Adaptation to Fracture}

Following condylar fracture of the mandible, patients adapt to the injury by compensation mechanism which is divided as follows:

- Skeletal

- Neuromuscular

- Dental

Intervention by the surgeons either by open or closed reduction minimizes the dental compensation. It is noted that there is a decreased masseter activity on the fractured site transferring load to a non-fractured site. This results in neuromuscular adaptation which may also be a protective phenomenon [8]. In case of an open reduction, there is minimum amount of neuromuscular adaptation. Usually a closed reduction results in an articulation which is inferior and anterior to the articular eminence which may limit the transitional movement. This can be avoided by open reduction and fixation. Minimum complications have been reported in the studies evaluating closed reduction in treatment of condylar fractures as pain and mouth opening were the only criteria which were evaluated. A statistically significant reduction in the incidence of malocclusion and lateral deviation on opening, along with an improved protrusive and laterotrusive movements, were noted in patients treated with surgical therapy vis-á-vis closed therapy in a recent meta-analysis report [10]. Compared to closed reduction where skeletal and neuromuscular adaptation is seen, in open reduction only neuromuscular adaption will take place following treatment. 


\subsection{Classification of Condylar Process Fractures}

Condylar fractures can be described as a fracture line above the mandibular foramen that runs from the posterior border of the ramus to sigmoid notch or the condylar head (Fig. 53.5). Literature mentions numerous classifications of condylar fractures. Most classifications described the fracture based on the anatomical site, displacement, and fracture level, inclined towards close reduction. With the advancement of imaging modalities and better understanding of open reduction procedures, classifications which are relevant are discussed.

Various terms describing the condylar fractures have appeared in the English literature (Fig. 53.6):

- No displacement-Fracture maintains anatomic position

- Deviation-Fragments are in primary contact

- Displacement-There is no contact of the fracture fragments

- Dislocation-Extra articulation of the joints

In 1927 Wassumund [11] differentiated between the head and neck fractures of the condyle. Early classification only described anatomical position but had no relevance in treatment as it did not document the angulation of displacement or dislocation. Condylar fractures were classified as:

- Base fracture

- Neck fracture

- Head fracture (diacapitular)

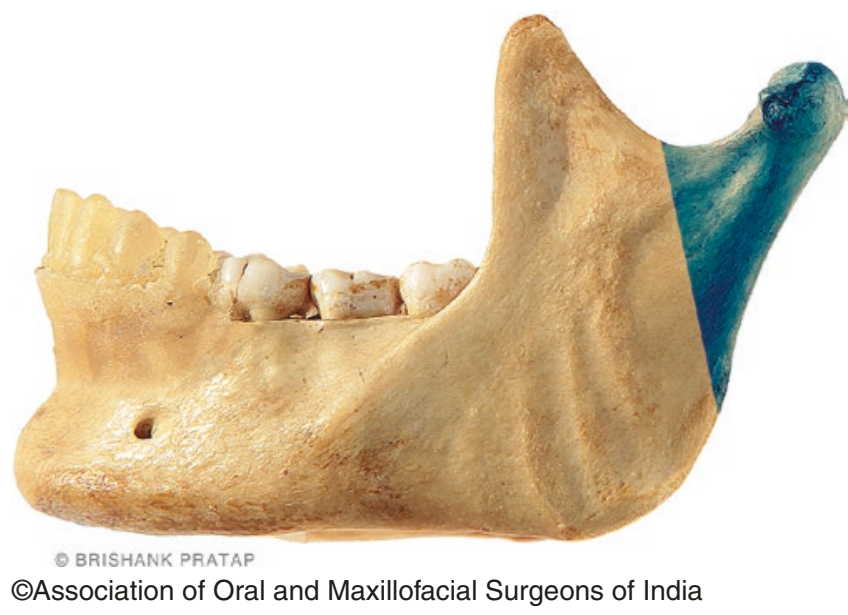

Fig. 53.5 Area of condylar fracture
MacLennan [12] was the first to differentiate between simple bending, displacement, and dislocation fractures of the condylar process.

Class I: no deviation (bending)

Class II: deviation (bending) at the fracture level

Class III: displacement (condylar head remains within fossa)

Class IV: dislocation (condylar head outside of fossa)

Spiessl and Schroll [13]. A classification well accepted in the European literature, which differentiated between fractures of the base and neck of the condyle, it also noted the range of angulation with deviation, displacement, or dislocation (Fig. 53.7).

- Type I: condylar neck fracture with no associated deviation/displacement

- Type II: low condylar neck fracture with deviation/ displacement

- Type III: high condylar neck fracture with deviation/ displacement

- IIIa: ventral

- IIIb: medial

- IIIc: lateral

- IIId: dorsal

- Type IV: low condylar neck fracture with dislocation

- Type V: high condylar neck fracture with dislocation

- Type VI: intracapsular fracture of the condylar head

There are numerous modifications of Spiessl and Scholl classifications and were given over a period of time as a result subtypes has evolved especially in type $\mathrm{V}$ and VI fractures. Modifications included Rasse [14], Neff et al. [15], Hlawitschka and Eckelt [16], and Loukota et al. [17].

- Type A: There is a continuous bony contact within the glenoid fossa, with a component of the remaining condylar head and the fracture supported with no loss of ramal height (Fig. 53.8a).

- Type B: Loss of support within the articulating fossa and with the loss of mandibular ramal height (Fig. 53.8b).

- Type C: The highest portion of the fracture is below the level of the lateral ligament, as a result there in a loss of ramal height (Fig. 53.8c). 
a

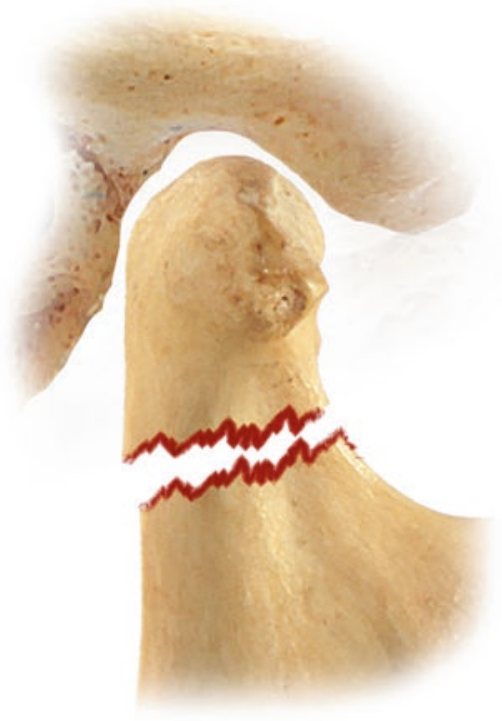

No Displacement

d

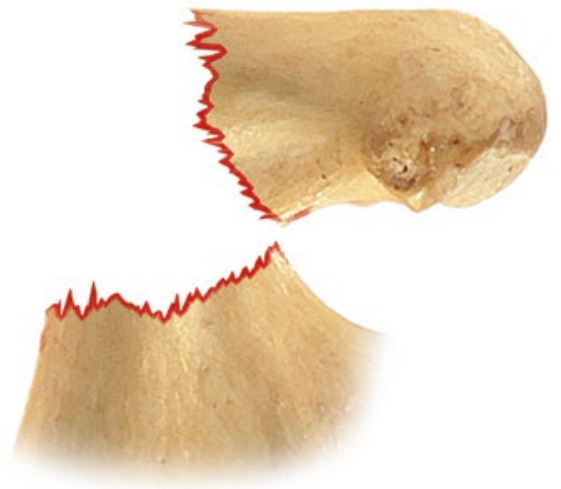

Dislocation (Deviation)

b

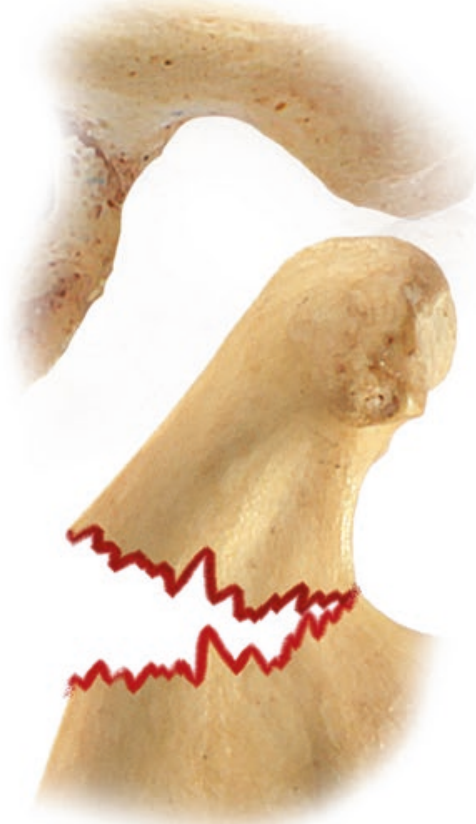

C

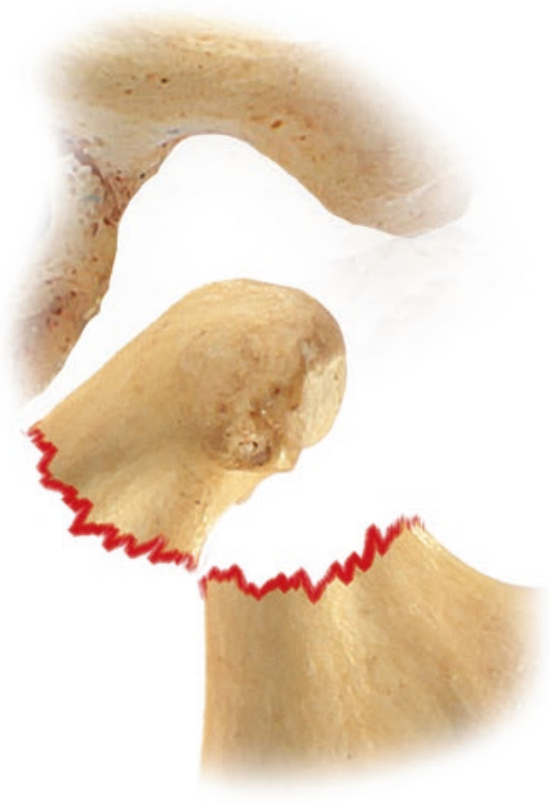

Displacement

Deviation

e

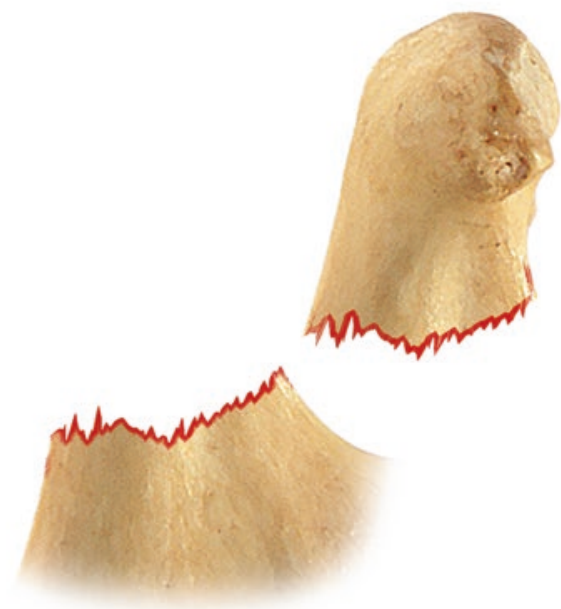

Dislocation (Displacement)

(C) BRISHANK PRATAP

CAssociation of Oral and Maxillofacial Surgeons of India

Fig. 53.6 (a) No displacement. (b) Deviation. (c) Displacement. (d) Dislocation (deviation). (e) Dislocation (displacement) 

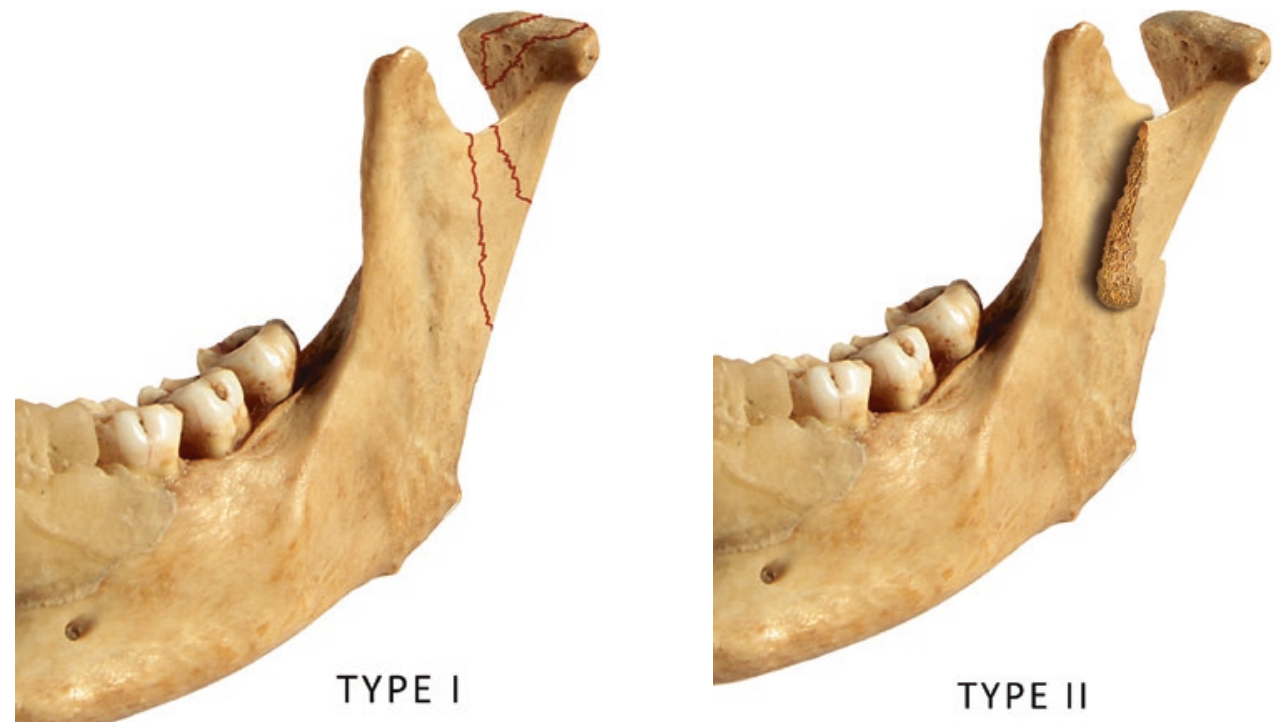

(c) BRISHANK PRATAP

(Q) BRISHANK PRATAP
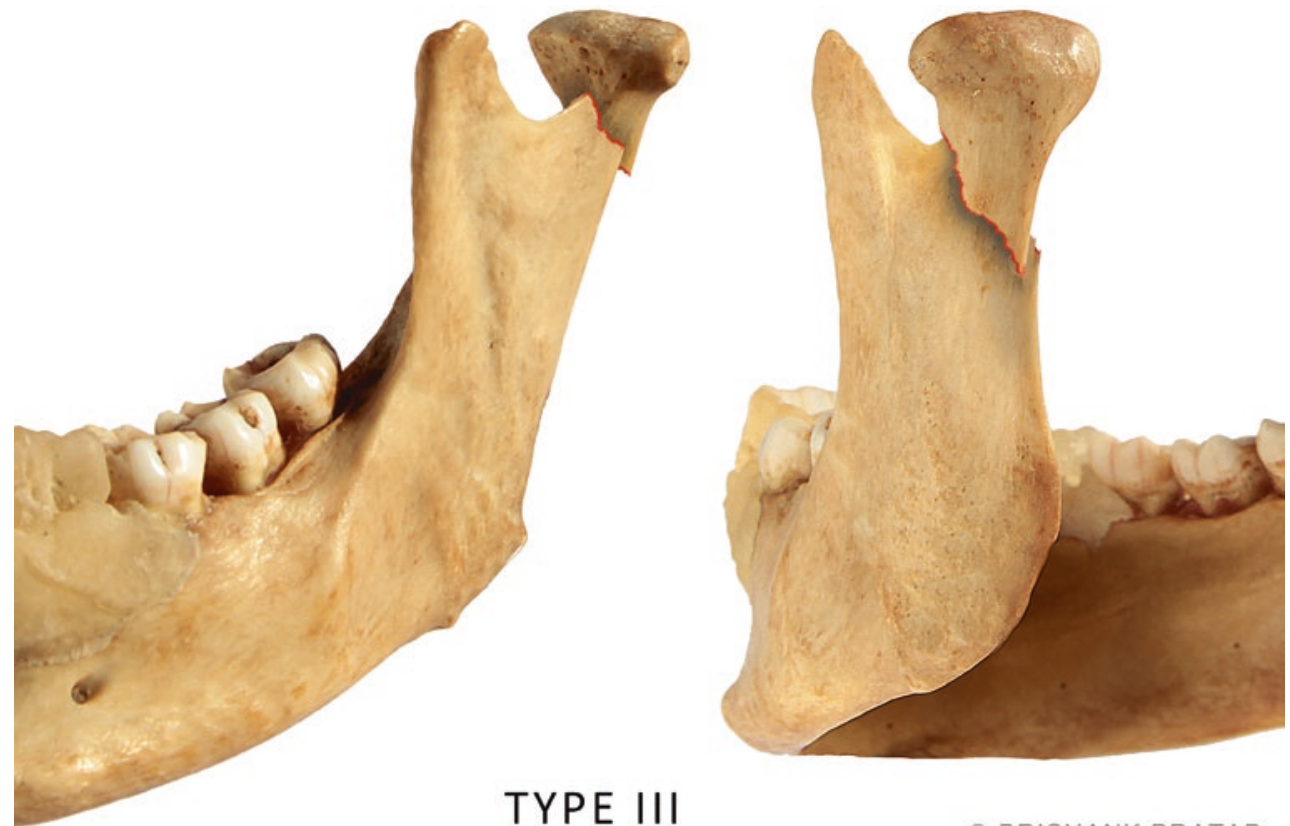

TYPE III

(c) BRISHANK PRATAP

Fig. 53.7 Types I-VI: Spiessl and Schroll classification 

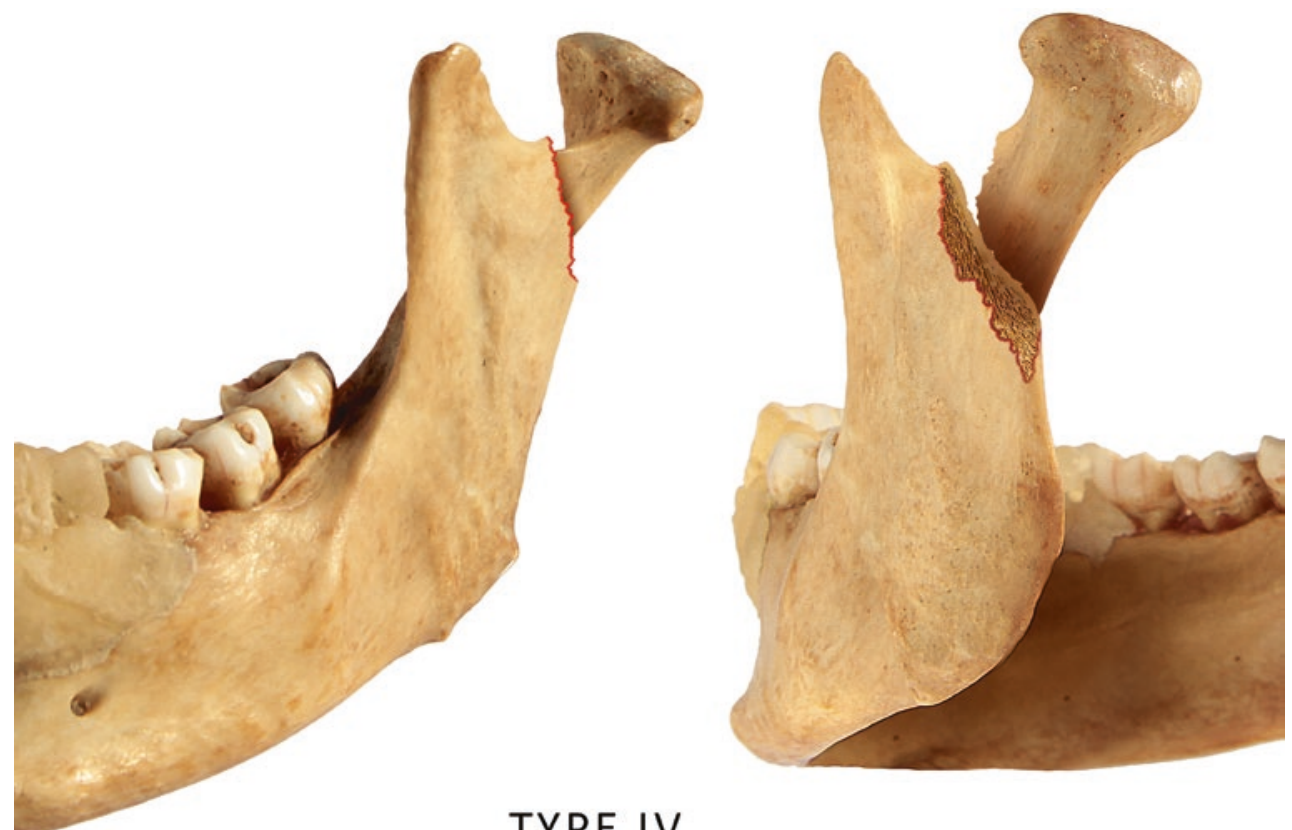

\section{TYPE IV}

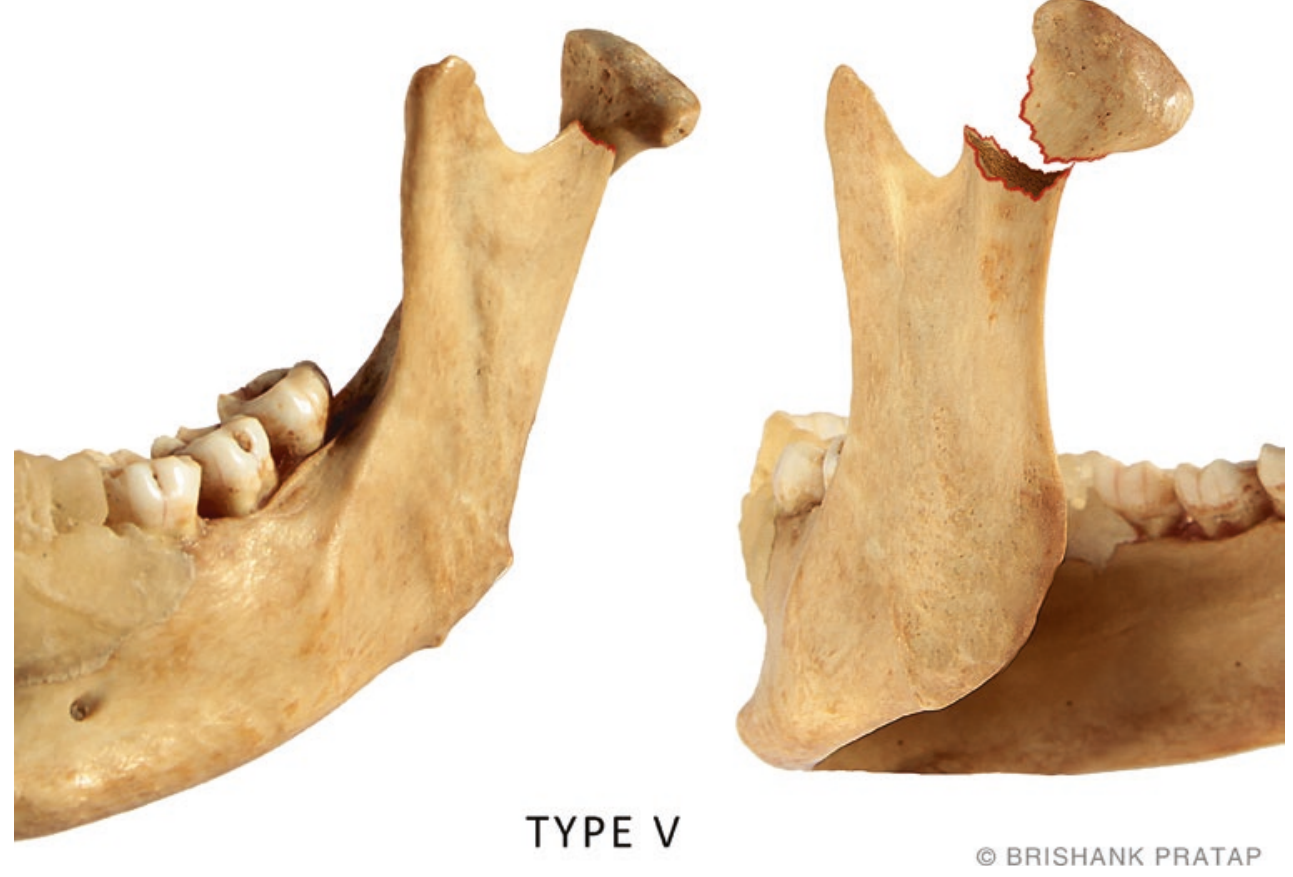

Fig. 53.7 (continued) 


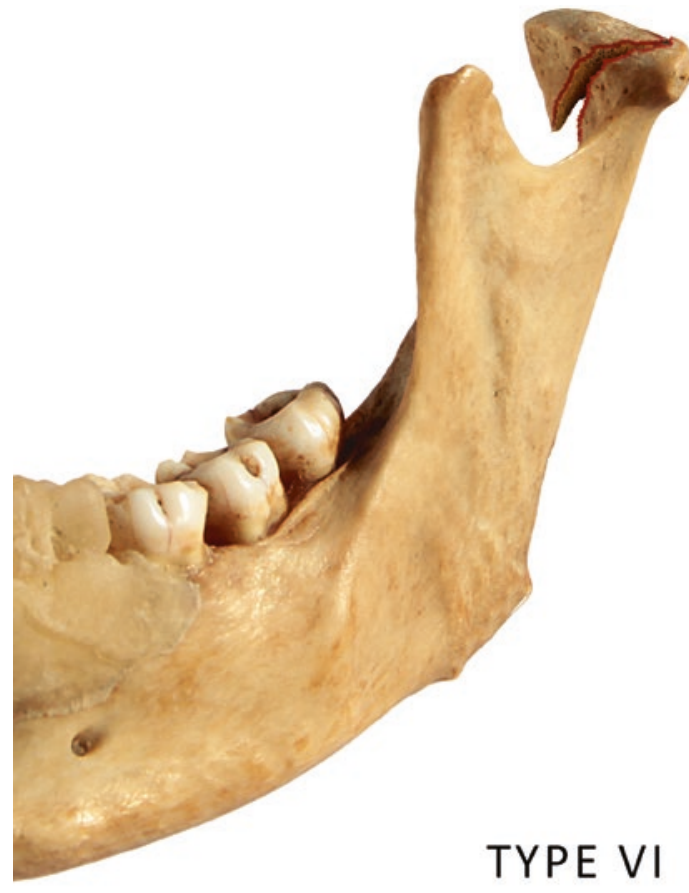

CAssociation of Oral and Maxillofacial Surgeons of India

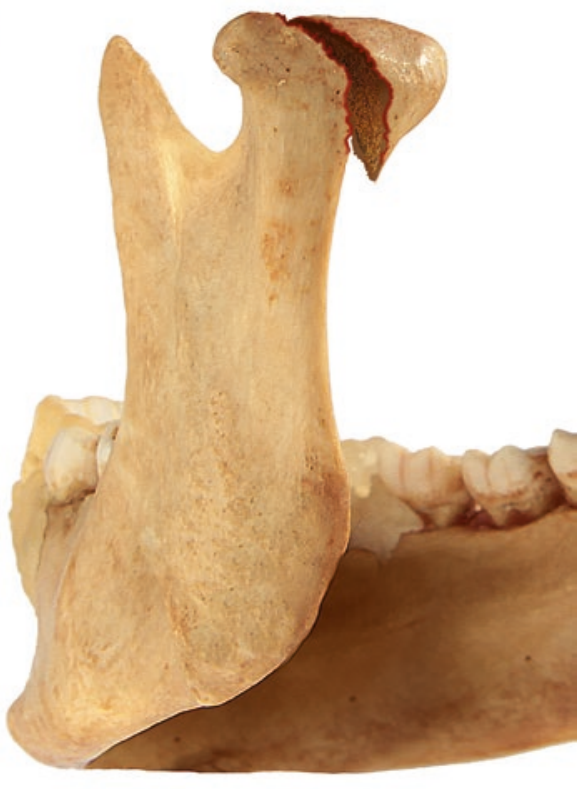

(c) BRISHANK PRATAP

Fig. 53.7 (continued)
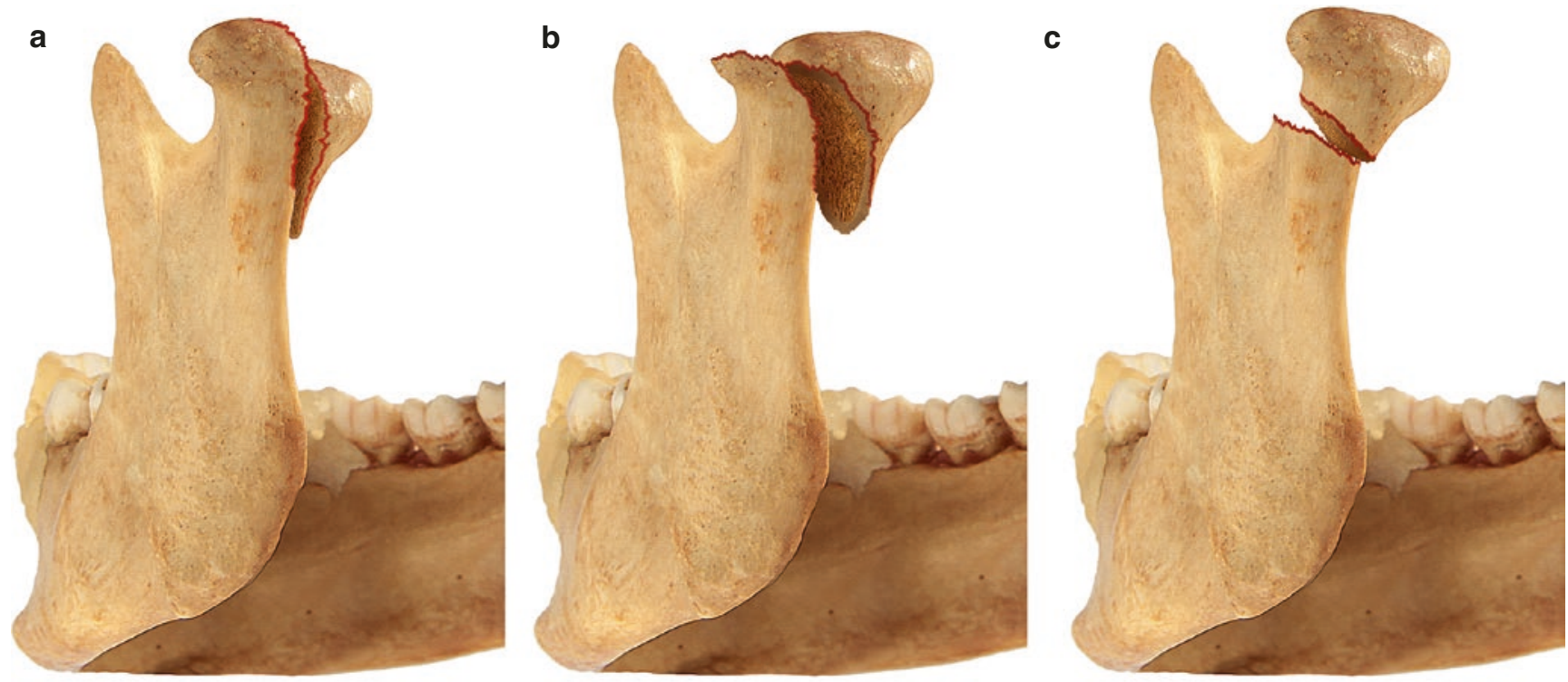

(C) BRISHANK PRATAP

Fig. 53.8 Modified classification Type A, B, C 
Lindahl [9] gave the most comprehensive classification. Although descriptive, it is a complicated classification [9].

1. Fracture level

(a) Condylar head

(b) Condylar neck

(c) Subcondylar/condylar base

2. Deviation and displacement

(a) Bending/deviation with medial overlapping segments

(b) Bending/deviation with lateral overlapping segments

(c) Bending/displacement without overlapping

(d) Nondisplaced fracture without deviation

3. Relation between condylar head and fossa

(a) No dislocation

(b) Slight dislocation

(c) Moderate dislocation

(d) Severe and/or complete dislocation

4. Condylar head fracture
(a) Horizontal
(b) Vertical
(c) Compression fracture

\section{Lindahl's Definition}

- Subcondylar fracture: The fracture line starts at the sigmoid notch and extends to the posterior border of the mandible.

- Condylar neck fracture: It is located at the condylar process which is below the level of the condylar head.

- Condylar head fracture: The majority of the fracture components or the whole fracture is contained within the TMJ capsule.

A most common classification of diacapitular fractures was given by He et al. [18]. The types of fractures that can be recognized are (Fig. 53.9):

- Type A-Lateral third portion of the condylar head has the fracture line, and there is reduction of the ramus height.

- Type B-Central third portion of the condylar head has the fracture line, and there is no reduction of the ramus height.

- Type C-Medial third portion of the condylar head has the fracture line, and there is no reduction of the ramus height.

- Type M-It is a fracture which is comminuted with multiple fragments, usually more than three, of the condylar head.

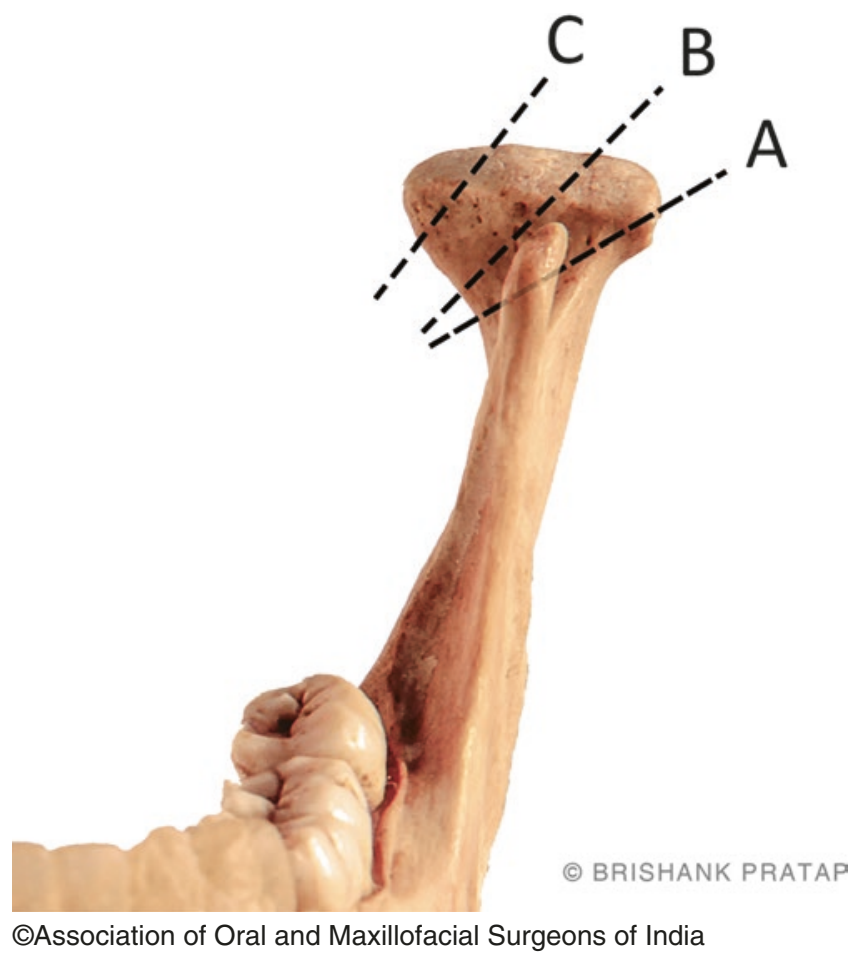

Fig. 53.9 Classification of diacapitular fractures (Type M not shown in figure)

Loukota et al. [19] proposed a system of classification for condylar processes fractures of the mandible. This classification was adopted by SOR group which is based on a line A drawn perpendicular from the lowest portion of the sigmoid notch to the posterior border of the mandible. This helps in identifying the anatomy of the mandibular ramus even in cases following severe trauma. A clarification is also given on the condylar head fracture, and it clearly defined the term minimal displacement.

Diacapitular fracture: Starting in the articular surface the fracture line may extend outside the TMJ capsule (Fig. 53.10a).

Condylar neck: Major portion of the fracture line which starts above the line A remains above it (Fig. 53.10b).

Condylar base: Major portion of the fracture line remains below the line $\mathrm{A}$, and it extends behind the mandibular foramen (Fig. 53.10c).

Minimal displacement: Less than $10^{\circ}$ displacement or $2 \mathrm{~mm}$ overlap of the bone edges or both.

AO Foundation in 2010 expanded on Ellis [20] classification with the determination of "high-neck" and "low-neck" fractures in the online AO Surgery Reference, which pro- 


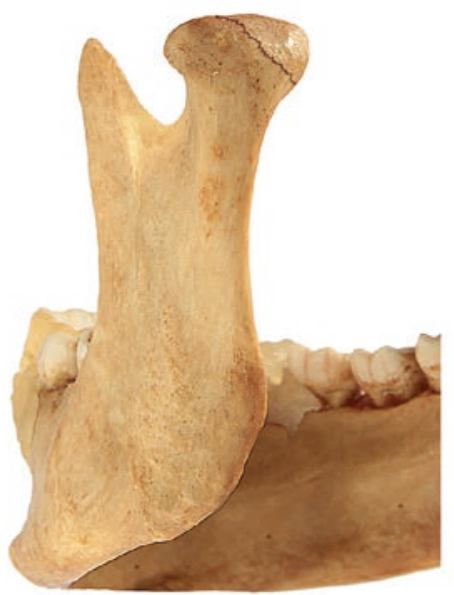

b

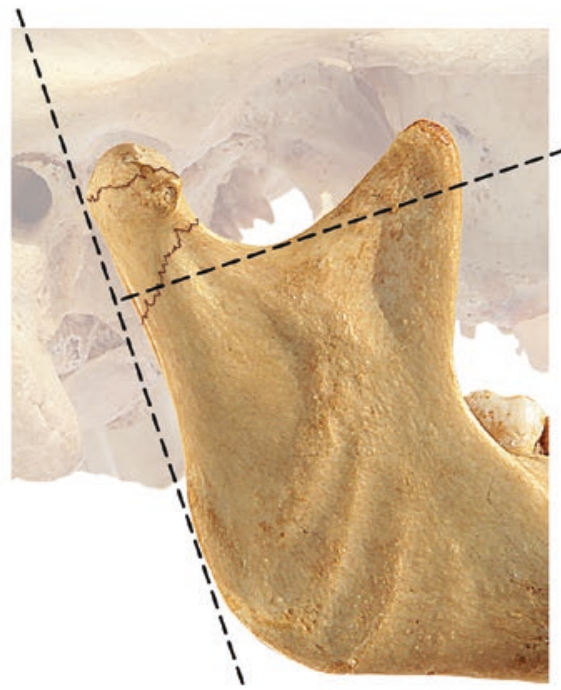

C

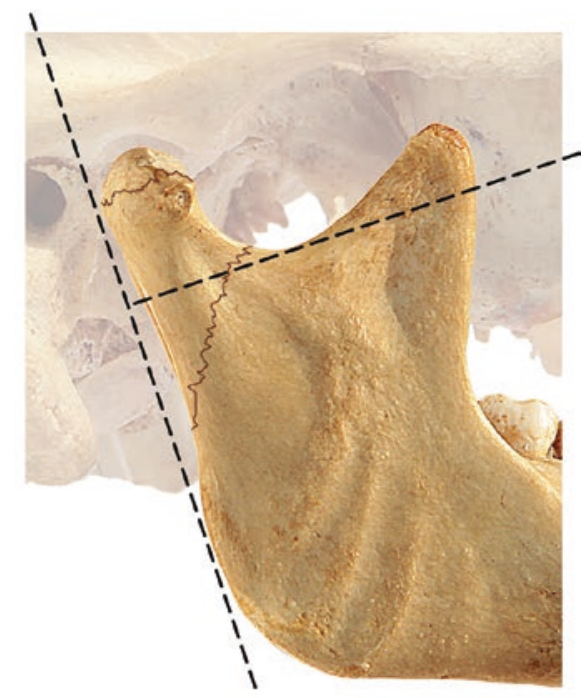

(c) BRISHANK PRATAP

CAssociation of Oral and Maxillofacial Surgeons of India

Fig. 53.10 (a) Dicapitular fracture. (b) Condylar neck. (c) Condylar base

vided a great detail to the location of "high and low" fractures as explained by Loukota:

- Line 1 runs parallels the posterior border of the mandible line.

- Line 2 as called the sigmoid notch line runs perpendicular to line 1 at the deepest portion the sigmoid notch.

- Line 3 is perpendicular to the first line and is below the lateral pole of condylar head.

- A line is also drawn half way between the line 2 and line 3 which differentiates between high- and low-neck fractures (Fig. 53.11).

Neff et al. [21] published the Comprehensive AOCMF Classification System: Condylar Process Fractures. It is a system that highlights fracture location, identification, displacement, comminution, and dislocation. Location of the condylar fracture is clearly identified:

- Condylar head: the condylar head reference line runs perpendicular to the posterior ramus below the lateral pole of the condylar head.

- Condylar neck: the sigmoid notch line running through the deepest point of the sigmoid notch perpendicular to the ramus line extending superiorly to the condylar head.

- Base of the condylar process: the sigmoid notch line running through the deepest point of the sigmoid notch perpendicular to the ramus line extending inferiorly.

In the early days classification systems for the condylar fractures were entirely focused in locating the fracture. This was followed by systems which added the relation of the condyle with the adjacent structure. Loukota [19] gave a

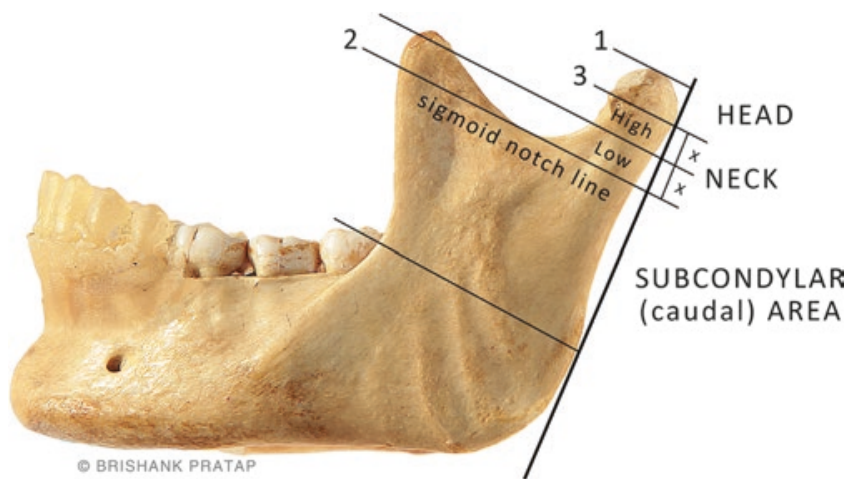

CAssociation of Oral and Maxillofacial Surgeons of India

Fig. 53.11 AO foundation classification

classification which accurately locates the fracture with reference to treatment which is a simple classification to follow.

The aim of classifying the condylar fractures of the mandible is to locate the type and nature of the fracture which in turn will give a clear understanding of the nature of injury. This in turn will help the surgeon make a decision on the modality of treatment which may be open or closed.

\subsection{Incidence and Pattern}

In the facial skeletal, one of the most common bones to fracture is the mandible. Analysis of the fracture of different anatomical sites of the mandible revealed that there was a 10-40\% incidence of condylar fractures [22-24]. Ellis et al. [25] published a study that showed condyle fractures repre- 
sented $29.3 \%$ of all mandibular fractures. Zachariades et al. [26] stated that $72 \%$ of the condylar fractures were associated with other mandibular fractures. Isolated condylar fractures were rare, and occurrence of malocclusion was more dependent on the site of fracture. Incidence of fractures of condylar base were $57 \%$, neck $31 \%$, and head $12 \%$ as reported by Maclennan [27]. Incidence of condylar head was the least with the majority fractures at the condylar base. Frequency of unilateral fractures is higher than the bilateral fractures.

The highest incidence of mandibular fractures in males was 20-30 years and females 30-40 years [25] with the male-tofemale ratio 3:1 [26]. Condylar fracture can result from direct or indirect trauma. The degree, direction, magnitude, and point of application of force determine the severity of displacement [27]. Personal violence [28] followed by fall [29$31]$ is the most common aetiology of condylar fractures.

\subsection{Clinical Features}

The patient may show mild to severe signs and symptoms following a condylar fracture. These are entirely dependent on the amount of displacement of the fractured fragments. Condylar fractures infrequently occurred in isolation and are generally associated with fractures of other sites of the facial bones. Surgeons may overlook subtle clinical features.

Signs and symptoms:

- Pain and swelling over the preauricular region

- Ecchymosis over the mastoid region

- CSF otorrhea

- Hollowness over the condylar region

- Restricted incisal opening

- Locked mandible
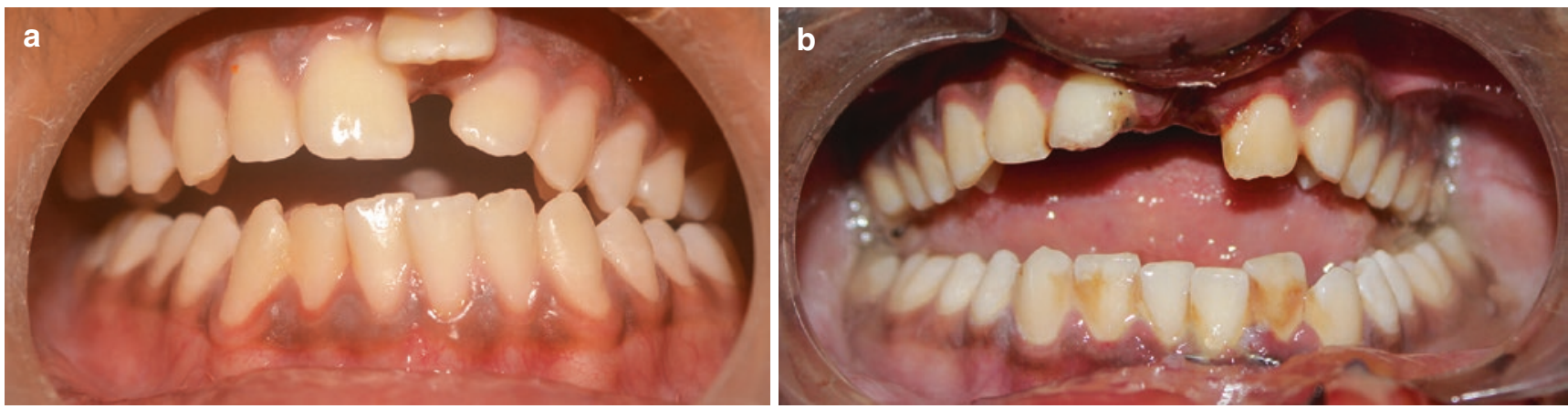

CAssociation of Oral and Maxillofacial Surgeons of India

\subsubsection{Condylar Fractures: Unilateral}

- Premature occlusion on the ipsilateral side (Fig. 53.12a).

- Open bite due to the loss of vertical height on the contralateral side.

- Affected side deviates on opening and is common because of the interruption of the action of the lateral pterygoid muscle.

- Limited laterotrusive movements away from the fractured side but may be maintained towards the fracture.

\subsubsection{Condylar Fractures: Bilateral}

- Bilateral loss of vertical height results in anterior open bite with posterior gagging (Fig. 53.12b).

- Restricted mouth opening

- May be associated with other fractures

\subsubsection{Radiographic Assessment}

Condylar fractures can be evaluated by a number of conventional views. A set of two radiographs are usually taken perpendicular to each other for optimum evaluation. However the assessment has become more descriptive with availability of specialized radiographs. Various views which can be taken to evaluate the condylar fracture are as follows (Fig. 53.13):

- Towne's view

- AP mandible coronal position

- Panorex

- CT scan

- MRI

Fig. 53.12 Occlusion post condylar fracture. (a) Unilateral condylar fracture of the left. (b) Bilateral condylar fracture 

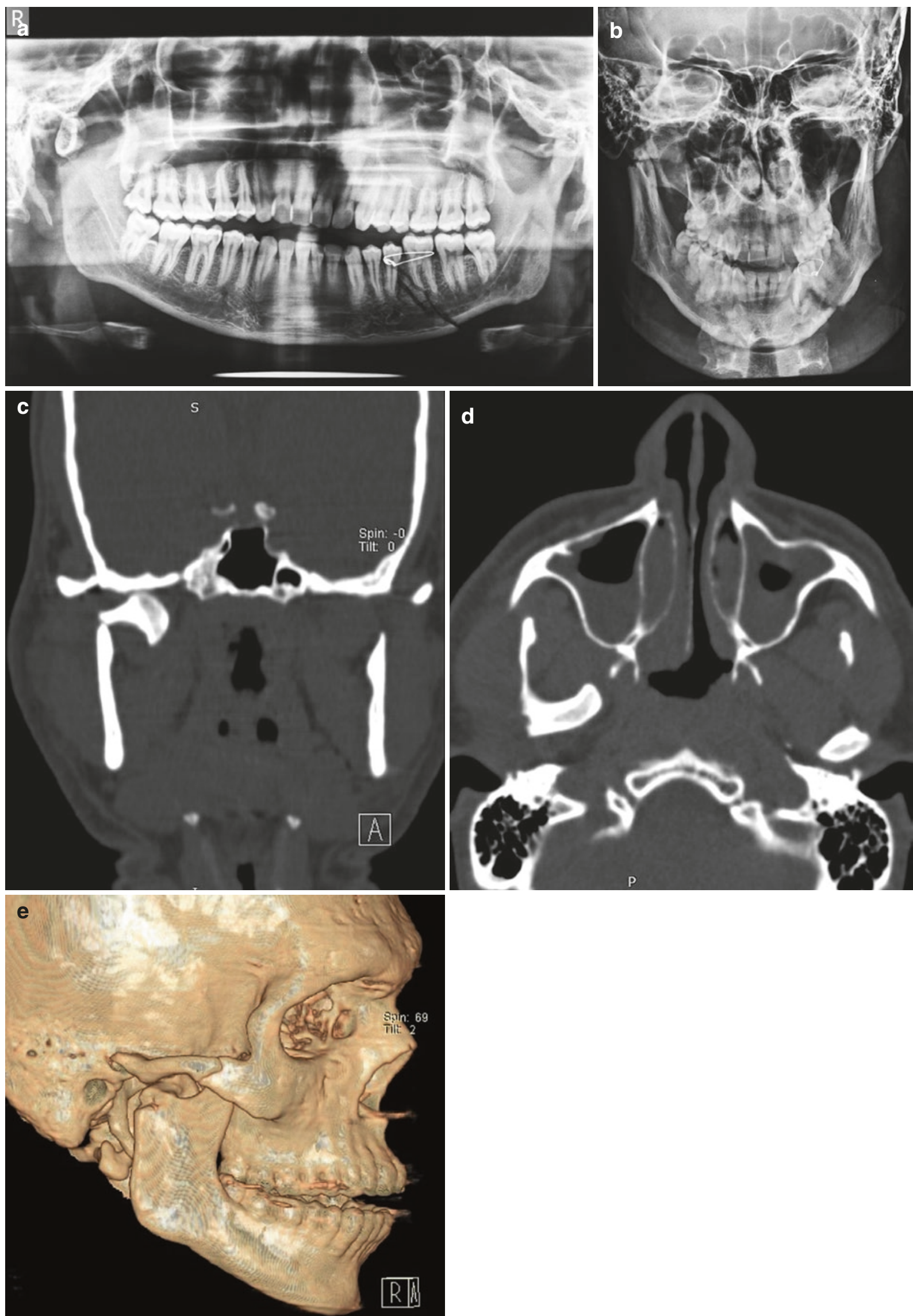

CAssociation of Oral and Maxillofacial Surgeons of India

Fig. 53.13 A case of unilateral fracture of the right side of condyle with a left body of mandible. (a) OPG. (b) PA mandible. (c) Coronal view. (d) Axial view. (e) $3 \mathrm{D}$ view of the CT scan 
However it may be noted that with conventional radiography, very limited information is available. CT scans in the three plains, namely, coronal, axial, and sagittal, with volumetric studies can reveal the true picture of the fracture both for the terms of evaluation and treatment planning. MRI are essential to evaluate the disc injuries specially in dislocation and intracapsular condylar fractures; however MRI are not taken as a routine practise

\subsection{Management}

Historically there has been no clear agreement among the surgeons on the line of management of the fractures of the condyle. The goals of treatment which were enumerated by Walker [32] (Box 53.2) are well accepted.

Box 53.2. Treatment Goals [32]

- No pain and minimum interincisal distance of $40 \mathrm{~mm}$ on opening the mouth.

- On excursions movements are good.

- Restore pre-injury occlusion.

- Good stable temporomandibular joints.

- Good symmetry of face and jaw.

- Good facial and jaw symmetry

\section{Box 53.3. Indications for Open Reduction}

\section{Zide and Kent's [33]}

\section{Absolute}

- Condyle displaced into middle cranial fossa

- Not possible to obtain adequate occlusion by closed reduction

- Lateral capsular displacement of condyle

- Presence of foreign body

\section{Relative}

- Bilateral condylar fracture in an edentulous patient without splint

- Comminuted midface fracture, prognathic or retrognathic jaws having associated bilateral condylar fractures

- Generalized periodontal conditions

- Jaws - totally or partially edentulous

- Unilateral condylar fractures with lack of base
Box 53.4. American Association of Oral and Maxillofacial

Surgeons [34]

- Evidence of fracture-clinical

- Evidence of fracture-radiographic

- Malocclusion associated with fractures

- Mandibular dysfunction

- Abnormal maxillo-mandibular relationship

- Foreign body invasion

- Lacerations and/or haemorrhage in external auditory canal

- Cases having hemotympanum, CSF otorrhea, effusion, or hemartorisis

Literature has indicated that closed reduction has been the treatment of choice. This may be due to the complexities involved with open reduction. Surgical approach is technically demanding and associated with complications in inexperienced hands. As a result, some centres have exclusively treated condylar fractures by closed reduction. However as opposed to closed reduction, a few centres follow a protocol for management where open reduction is treatment of choice. Patients managed by surgical treatment have a superior outcome in term of post-treatment malocclusion, protrusion, laterotrusion, and lateral deviation during mouth opening. However, there was a higher infection rate as compared to non-surgical treatment. However, there is no statistical difference in post-treatment pain and maximum mouth opening in the two modalities of management [10]. Management can be divided as non-operative and operative (Box 53.6).

\subsubsection{Non-operative}

Some patients can be managed by observations provided they have a minimal nondisplaced fracture, dentate with a stable occlusion and having minimum pain. An important factor is that the patient must be complaint. At the onset of the treatment, patient must be explained about the possibility of additional treatment in the form of closed reduction which may be required.

Protocol followed is as follows:

1. Diet: There is no restriction on the diet; generally a patient would be restricted to a soft diet in order to avoid pain.

2. Rehabilitation: Patient is instructed to perform exercises of the jaw such that all the excursion movements are carried out. Goals of rehabilitation are mentioned in the (Box 53.8). 


\section{Box 53.5. Indication for Open and Closed Reduction}

Fonseca [35] adapted from references [36-43]

\section{Absolute}

- Condyle displaced into middle cranial fossa

- Presence of foreign body

- Extracapsular displacement of condyle laterally

- Malocclusion not amenable to closed reduction (e.g., functional reduction of ramus height)

\section{Strong evidence for open reduction}

- Bilaterally fractured condyles

- Condyle displacement grossly $>45^{\circ}$ (severely displaced)

- Anatomic reduction of ramus height $\geq 2 \mathrm{~mm}$

- Condylar fractures with an unstable base (associated midface fractures)

- Unstable occlusion generally seen in periodontal disease, less than three teeth per quadrant

- Condylar fractures for which adequate physiotherapy is impossible

\section{Mixed evidence for open reduction}

- Moderate condylar displacement, $10-45^{\circ}$

\section{When to treat with closed reduction}

- Nondisplaced or incomplete fractures

- Isolated intracapsular fractures

- Condylar fractures in children (except for absolute indications)

- Reproducible occlusion without dropback or with dropback that returns to midline on release of posterior force

- Medical illness or injury that inhibits ability to receive extended general anaesthesia

\section{Box 53.6. Management of Condylar Fractures}

\section{Non-operative:}

- Observation, physiotherapy, etc.

\section{Operative:}

- Closed procedures:

- MMF (arch bars or screws-elastic or wire)

- Open reduction and internal fixation (ORIF) - Approach is determined by:

(i) Surgeon preference

(ii) Fracture location

(iii) Type of fixation

\section{Box 53.7. Factors Taken into Consideration for}

Treatment

- Location of the fracture

- Amount of vertical reduction in height of the ramus

- Degree of angulation

- Relation of condylar head to the glenoid fossa

- Fragmentation pattern (simple versus complex)

- Association with other mandibular injuries

- Dental occlusion/status of dentition

- Association with other facial bone injuries

- Association with systemic injuries

- Association with the condition of the patient (comorbidity factors)

- Foreign body in temporomandibular joint (TMJ)

\section{Box 53.8. Closed Reduction}

Advantages

- Relatively safe procedure

- No injuries to vital structures

- Hospitalization may not be required

\section{Disadvantage}

- Long period of intermaxillary fixation

- Growth disturbances can occur in children

- Success depends on patients cooperation

- Long-term follow

- Contraindicated in medically compromised

- Challenge in partially or totally edentulous patients

3. Follow-up: Recall visit is scheduled after 1 week. At this visit progress is recorded. Next visit is scheduled after 2 weeks if the patient is compliant. In case the progress is not satisfactory frequent follow-up would be required or a change in treatment plan.

\subsubsection{Closed Reduction}

Closed reduction is a misnomer. It is never possible to achieve anatomic reduction as seen in management of other fractures. Closed reduction relies on the functional adaptation where a stable occlusion is achieved. Advantage of this technique is that it is minimally invasive and may not require hospitalization. It is entirely possible to carry out the procedure under local anaesthesia. However adaptation is never complete in adults as opposed to children. It may be possible to treat all types of condylar process fractures by this technique, but the surgeon must 
exercise his judgement based on the case and patient requirements. Closed reduction may involve the following:

1. Maxillomandibular fixation (MMF): Some surgeons prefer period of MMF which may range over 2-6 weeks. MMF can be obtained by using arch bars, Ivy loops, IMF screws or any other method a surgeon is comfortable; however method used will depend on the use of elastics or wires, and MMF may entirely be based on the level of fracture. The reader is advised to refer Chap. 50 of this book for details on various wiring and IMF techniques The lower the fracture, the longer the period of immobilization. In children immobilization may range from 7 to 10 days as there are high chances of developing ankylosis. This is followed by functional treatment.

2. Functional treatment: At times only, functional treatment may be followed. This treatment relies on guiding elastics and active movements. Elastics are given to achieve repeatable occlusion. Initially heavy elastics are placed and then slowly shifted to light elastics. During the meals elastics are removed. After an initial period of 2-4 weeks, elastics are placed only during the night. Minimum elastics must be used as the aim is to permit maximum mobility of the jaw. Functional treatment can be supported by myofunctional orthodontic treatment employing activator therapy. Myofunctional therapy should be started as soon as the mouth opening enables taking dental impressions.

\subsubsection{Open Reduction and Fixation}

This modality is technically challenging due to the complexities in terms of anatomy, approach, and fixation. It has been observed that by achieving anatomical reduction irrespective of the type of fixation used, it will result in restoring back the skeletal architecture. This in turn would require only neuromuscular adaptation for full recovery of the patient. According to the reports, this may be the reason for open management to be superior to the closed [36].

Surgical approaches to the condylar fracture are entirely dependent on the following factors (Fig. 53.14):

1. Location of the injury

2. Type of osteosynthesis

Incisions used to approach the fractures are divided as
1. Intraoral
2. Retromandibular
3. Submandibular/ periangular
4. Preauricular/ retroauricular

\section{Box 53.9. Open Reduction and Fixation}

Advantages

- Anatomic reduction of fractures

- Short or no intermaxillary fixation

- Early function

\section{Disadvantage}

- Complications such as scar and injuries to neurovascular structures

- Infections

- Hospitalization required

- High cost of treatment

- Steep learning curve for surgeon

\subsubsection{Submandibular/Periangular}

(Fig. 53.15a, b) (Video 53.1)

This is an approach most maxillofacial surgeons are familiar with in their practise popularly known as Risdon approach. It exposes the base along with the neck of the condyle. Incision can either be parallel to the lower border or placed in a skin crease for maximum cosmetic results. For the condylar, fracture's incision is extended backward and upward to give a maximum exposure hence also referred to as periangular incision. The marginal mandibular nerve is protected by marking the incision $2-3 \mathrm{~cm}$ below the lower border of the mandible. Incision transverses through the skin, subcutaneous fat, and platysma. A superior platysmal dissection will expose the marginal mandibular nerve; however this may not be necessary. After dissection of the platysma, superficial layer of deep cervical fascia is transected; this may expose the facial artery and vein. These may be required to be ligated and reflected superiorly. This will protect the marginal mandibular nerve. Then pterygomasseteric sling is divided and periosteum reflected to expose the lower border of the mandible. This gives an adequate exposure for osteosynthesis.

A modification of the submandibular/periangular approach known as the high submandibular approach or the high cervical transmassetric anteroparotid approach provides good aesthetics and reduces the chances of damage to the facial nerve [44]. A curved incision measuring three to five $\mathrm{cm}$ in length is placed about $1 \mathrm{~cm}$ from the angle of mandible [45]. This is followed by layered dissection. An avascular pouch is created superiorly, and the pterygomasseteric sling is identified. Stripping the masseter muscles of its attachments will lead to the exposure of the fracture [46] (Video 53.2). 


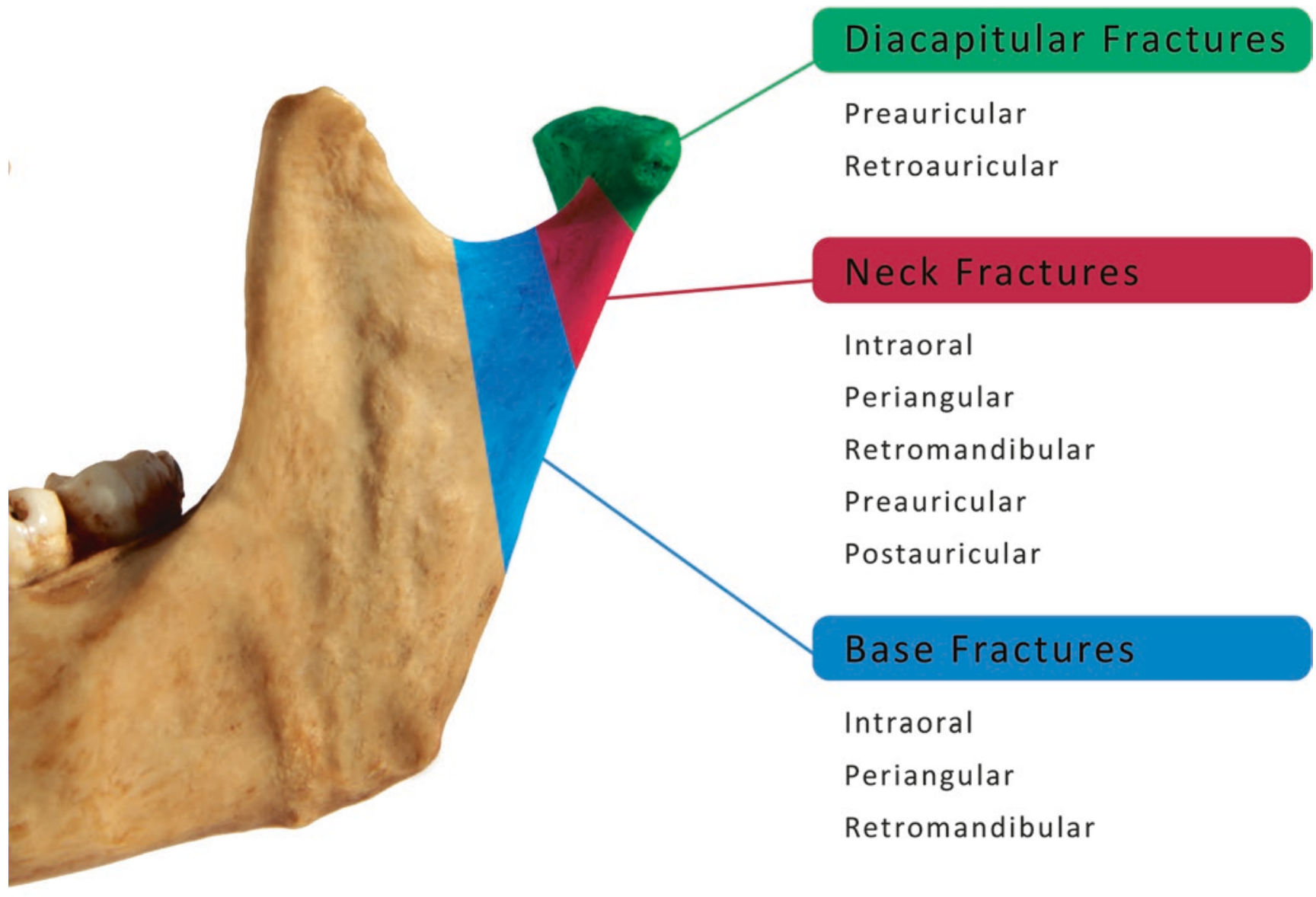

\section{(c) BRISHANK PRATAP}

CAssociation of Oral and Maxillofacial Surgeons of India

Fig. 53.14 Various incisions possible for condylar fractures based on location
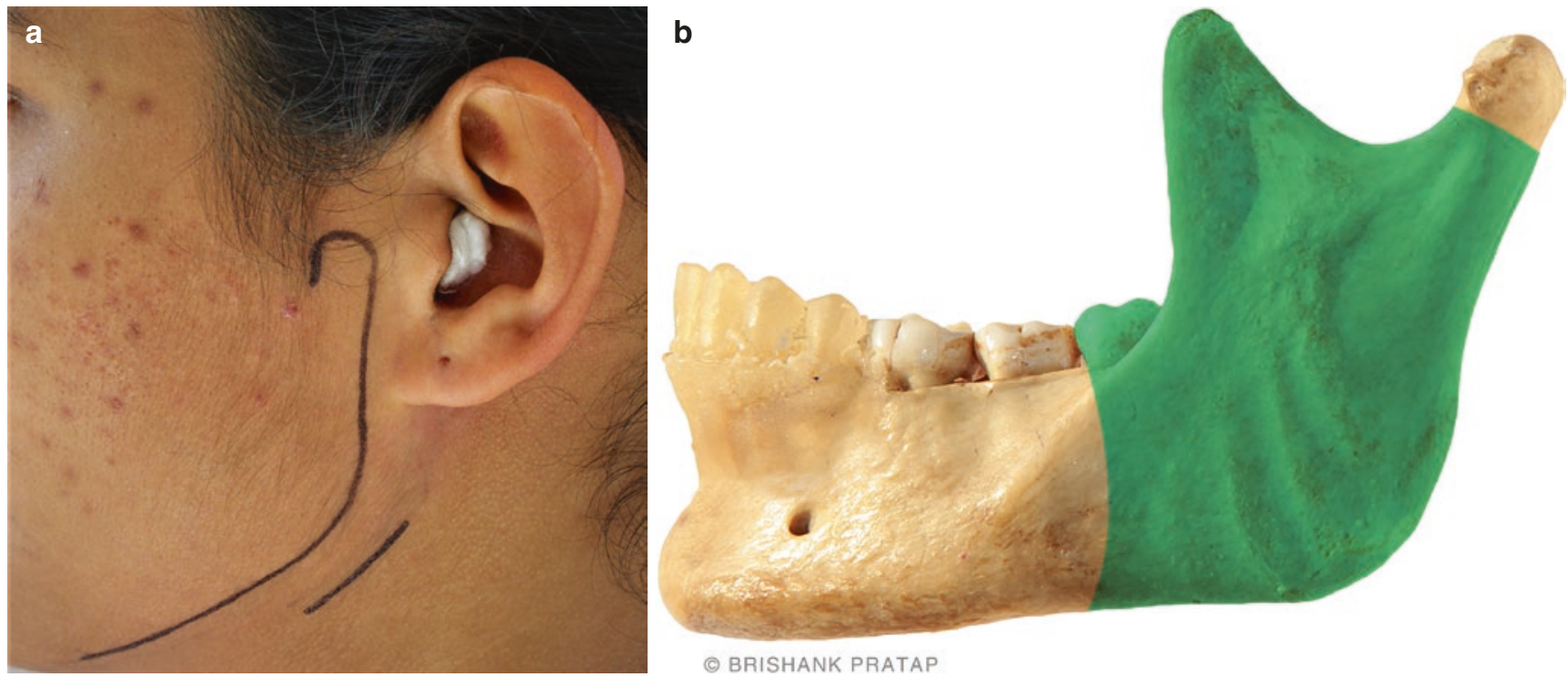

CAssociation of Oral and Maxillofacial Surgeons of India

Fig. 53.15 (a) Incision for submandibular/periangular approach. (b) Area exposed marked green in the mandible 


\subsubsection{Retromandibular (Fig. 53.16a, b)} (Video 53.3)

Entire posterior border can be exposed via the retromandibular approach [47]; hence this approach is useful in treating fracture of the condylar neck and the base. The anatomic structures encountered in this approach are the main trunk of the facial nerve and retromandibular vein. It has two main variations transparotid and retroparotid. In both the variation marking of the incision is $5-10 \mathrm{~mm}$ below the lobule of the ear, parallel to the posterior border usually $3-4 \mathrm{~cm}$ long.

\section{Transparotid Approach}

In this approach incision is extends from the skin to the subcutaneous tissue, and it is undermined to reach the parotid capsule which is divided horizontally between the path of the buccal and zygomatic branches of the facial nerve. Dissection is carried out parallel to the direction of the facial nerve branches, and it is not important to locate the branches. Pterygomasseteric sling is sectioned, and periosteal flap elevated to expose the posterior border of the mandible.

\section{Retroparotid Approach}

In this approach parotid gland is lifted rather than transected to approach the posterior border of the mandible. Incision in this approach is placed more posterior as compared to transparotid approach as a result exposure is also restricted. After the parotid fascia is identified, dissection is carried out behind the gland. The gland is lifted to expose the posterior border; from here the dissection carried out is the same as the transparotid approach.
The wound is closed in layers to avoid dead space. Also, the parotid fascia should be sutured tightly to prevent sialocele or parotid fistula. Drains can also be placed.

\subsubsection{Preauricular Approach (Fig. 53.17a, b)} (Video 53.4)

This incision is most commonly used by the surgeons in the TM joint surgeries. Diacapitular fractures are approached via this approach [48]. Branches of facial nerve are involved in this approach along with the superficial temporal artery and vein. Incision is placed along the crease of the skin following the tragus and helix of the ear which can be extended in the temple region. This extension on the temple minimizes traction and prevents weakness of facial nerve. Incision is carried from the skin to the subcutaneous tissue till the white glistening temporal fascia is reached. Root of the zygoma is palpated, and an oblique incision is given parallel to the frontal branch of facial nerve. Superficial temporal fascia is incised, and a periosteal elevator is inserted below the fascia to strip the periosteum of the zygomatic arch. This will expose the capsule of the temporomandibular joint. Capsule is incised in an open method to expose the head of the condyle. The neck is exposed by doing a subperiosteal dissection. Closure is done in layers first being the capsule followed by temporalis fascia, subcutaneous tissue, and the skin. The main disadvantage of this approach is an unaesthetic scar. This can be overcome by placing the incision endurally. The scar hides behind the tragus, but it can cause perichondritis.
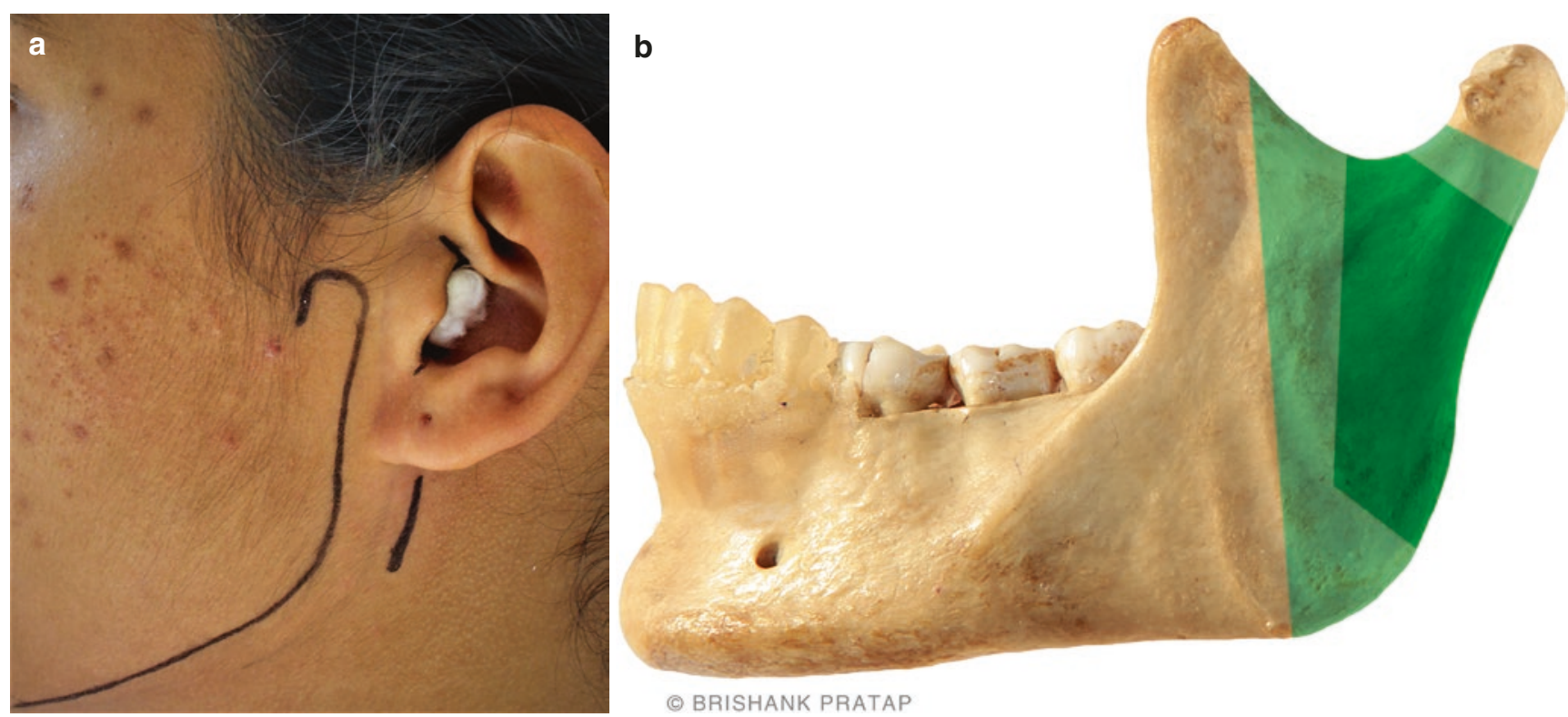

CAssociation of Oral and Maxillofacial Surgeons of India

Fig. 53.16 (a) Incision for retromandibular approach. (b) Area exposed marked in mandible (dark green, retro parotid exposure; light green, transparotid exposure) 

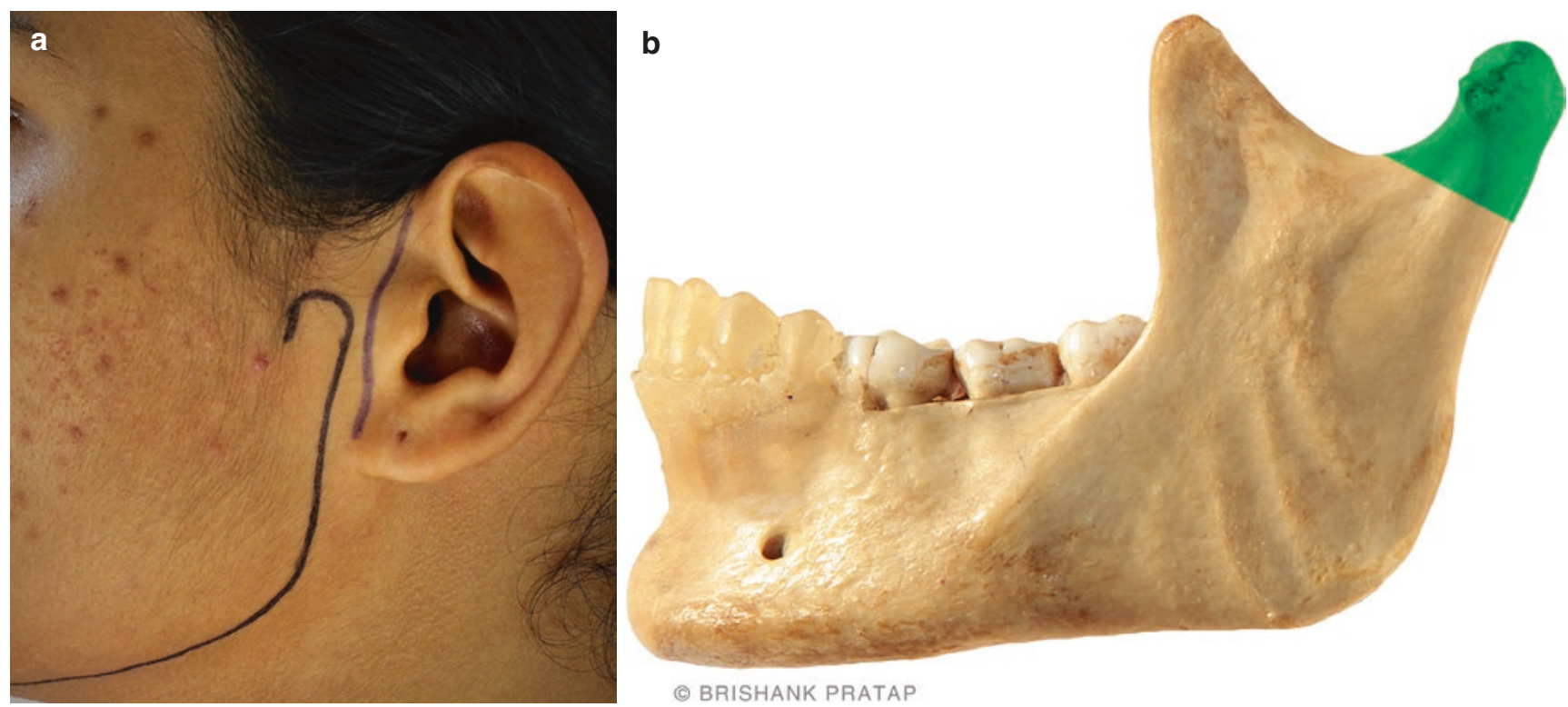

(C)Association of Oral and Maxillofacial Surgeons of India

Fig. 53.17 (a) Preauricular approach incision. (b) Area exposed marked in the mandible

\subsubsection{Retroauricular Approach}

This is an approach which will provide best cosmetic results. However major disadvantage is that it can result in stenosis of the external auditory canal. Also, the closure takes a longer time. Incision runs parallel to postauricular flexure approximately $3 \mathrm{~mm}$ behind it. Skin followed by postauricular muscles and fascia overlying mastoid are incised. External auditory canal is identified and completely transected at bony cartilaginous junction. Temporalis fascia is identified, and from here dissection followed is similar to preauricular approach to expose the condylar head. Closure is done in layers with a special attention given to the external auditory canal.

\subsubsection{Reduction}

After the adequate exposure of the fractured fragments reduction is achieved under direct vision. If the distal fragment is placed laterally, reduction tends to be easy. However, in most of the cases, the fragments tend to be displaced medially resulting from the pull of lateral pterygoid muscle. A medially displaced fragment must be lateralized before an attempt is made to reduce the fracture. For easy manipulation, a plate with a single screw is fixed on the distal fragment. This will help in easy lateralization of the distal fragment and prevent the fragment from slipping back as the lower end of the plate acts as a rest on the proximal segment. Before an attempt is made to reduce the fracture, manual traction is applied to the mandible so that the vertical height of the posterior mandible is restored. This can be achieved as follows (Fig. 53.18a-d):

1. Manual digital traction: Thumb is placed on the lower teeth and fingers support the lower border. Mandible is pulled in inferior and anterior direction.

2. Bite block: A bite block is placed on the same side of the condylar fracture in the molar region. This will result in inferior distraction of the mandible with rotation.

3. Transosseous wire: A transosseous wire can be passed along the posteroinferior border of the mandible. A traction is applied on this wire in an inferior and anterior direction.

Once the fracture is reduced with the help of a clamp in the lowermost hole of the plate, pressure is applied to keep the fractured end in place. Figure 53.19a-d shows the reduction and fixation of a medially displaced condyle fracture.

In a case where two plates are planned for fixation, the smaller plate along the anterior border of the condyle is fixed first with a screw. Once the anterior plate is fixed on the distal segment, similar steps are followed as mentioned earlier for single plate for reduction and fixation.

Sequencing the case of multiple fractures is as follows:

1. Fractures with contralateral condylar fractures-Fractures in the tooth bearing anterior segment are fixed before the condyle is fixed. 

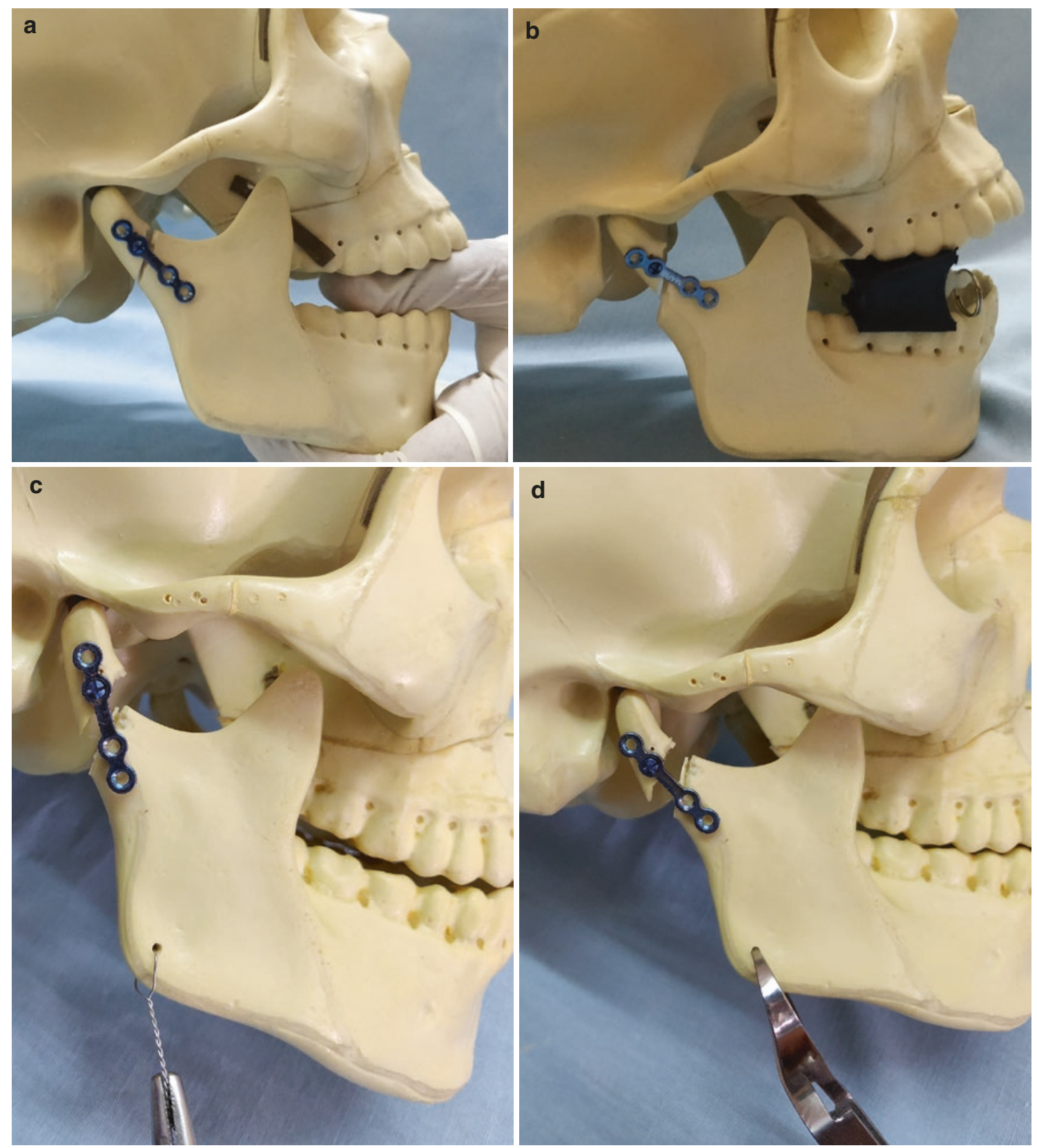

CAssociation of Oral and Maxillofacial Surgeons of India

Fig. 53.18 (a) Manual digital reduction. (b) Traction using bite block. (c) Transosseous wiring. (d) Towel clip

2. Bilateral condylar fracture with anterior mandible-In these cases there can be flaying of the mandible resulting in increase of transverse dimension of mandible. Anterior fractures are reduced and fixed taking into consideration into the lingual reduction. Anterior fractures are fixed before the posterior.

3. Panfacial trauma-Principal remains the same, mandible is fixed as mentioned above before the midface fractures are reduced and fixed. This may change depending on the sequence followed for fixation of panfacial fractures
53.7.5 Fixation Techniques (Fig. 53.20a-d),

(Case 1: Fig. 53.21a-b),

(Case 2: Fig. 53.22),

(Case 3: Fig. 53.23a-e),

(Case 4: Fig 53.24a-d)

The most significant advances that have taken place in the management of fracture of condylar process include the osteosynthesis material and the technique. Fixation with titanium plates and screws has given optimal results when adequate bone, proper site selection with proper techniques 

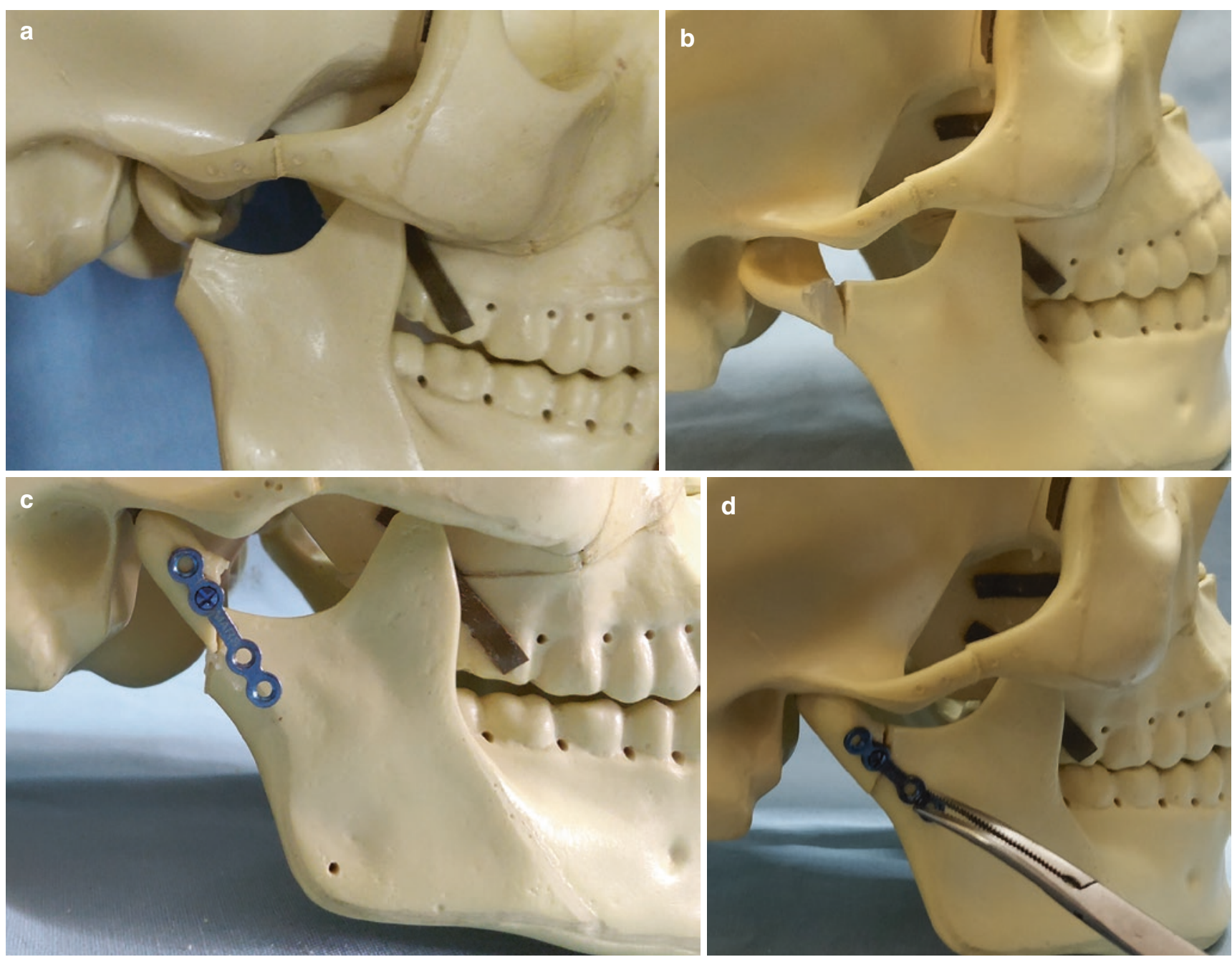

CAssociation of Oral and Maxillofacial Surgeons of India

Fig. 53.19 (a) Medially displaced condylar fracture. (b) Fracture lateralized. (c) Distal segment secured with a plate. (d) Fracture reduced

followed [49]. At the time of surgery fixation, technique is selected based on the following parameters:

1. Fracture morphology

2. Amount of bone available

3. Surgeon preference

Fixation can be in the form of one plate, two plates, hybrid plates, lag screws, or restorable plates. Studies have shown that use of two plates is superior to one plate $[40,50]$. Two plates must be used for lower level fractures to overcome tension and stress in the neck region by placing plates along the anterior and posterior border in a triangular fashion (Fig. 53.20a-d). In cases where there is limited bone, available fixation can be done with heavier single plate. Single plate is fixed along the long axis of the condyle. There are many types of hybrid plates available. These are designed to incorporate the principle of two plates in a single plate. However, this makes the plates bulky as a result it may be at times difficult to fix them especially when there is limited bone available. Irrespective of the type of plate used, there should be at least two screws on either side of fracture.

Fixation of condylar head is a challenge because of the limited space available and the fractures are intracapsular. In addition, there could be multiple small fragments and associated injury to the disc and the capsule which may be required to be repaired. Several osteosynthesis techniques are available for fixation like the mini plates, stainless steel wire, standard lag screws, resorbable screws, resorbable pins, and cannulated lag screws (Fig. 53.25). Reduction and fixation of the condylar head is technically challenging as the small fragments can easily necrose if stripping of the muscle is done. Use of two lag screws would be idle as it will prevent the reduced fragments from displacement during function, but times it may not be possible to fix two screws due to limited space Table 53.1 [51].

Intraoral endosocpic approach for treatment of condylar fractures is given in detail in Chap. 54 of this book. 

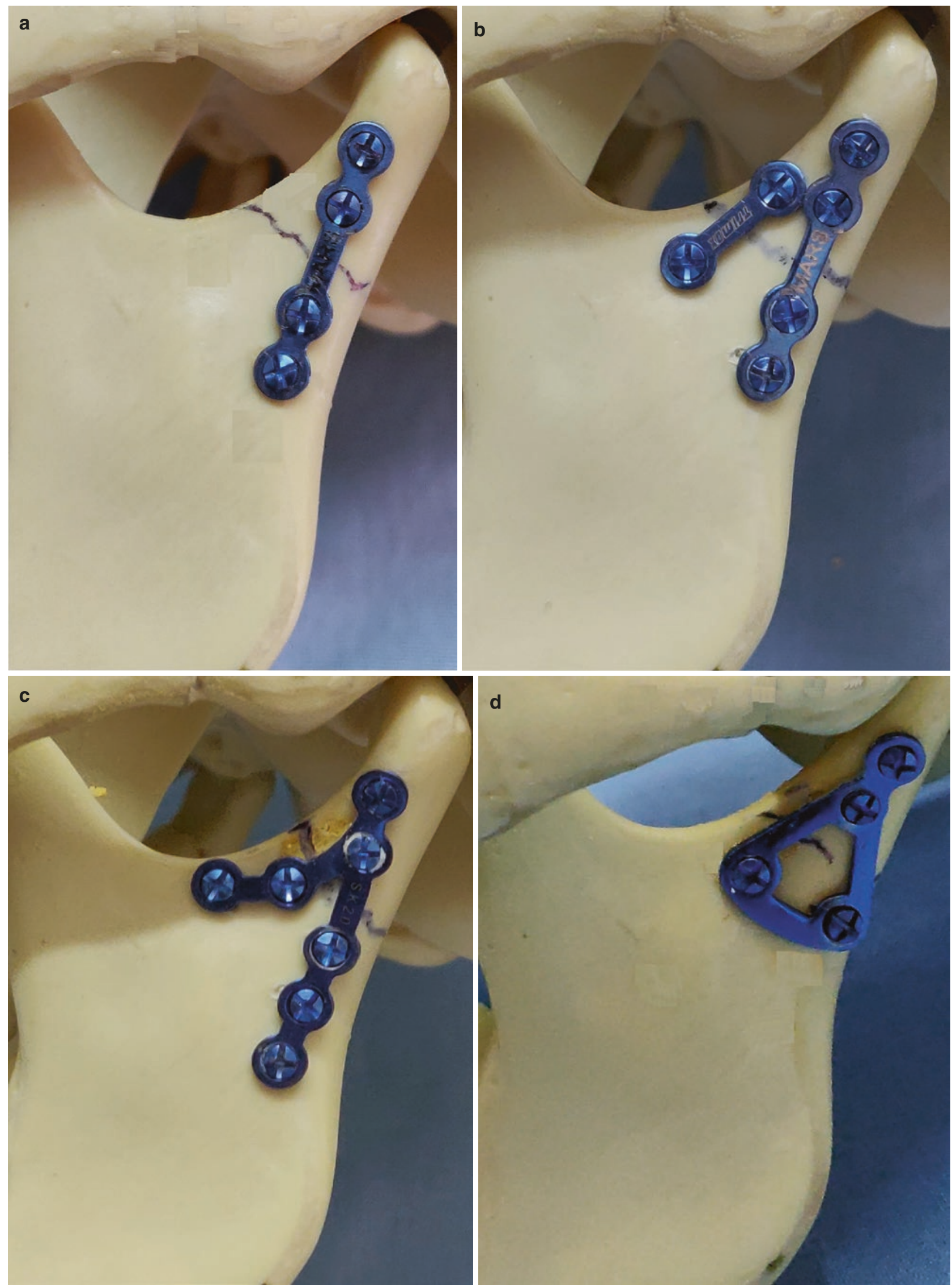

CAssociation of Oral and Maxillofacial Surgeons of India

Fig. 53.20 (a) Single plate. (b) Two plates. (c) Lambda plate. (d) Delta plate 

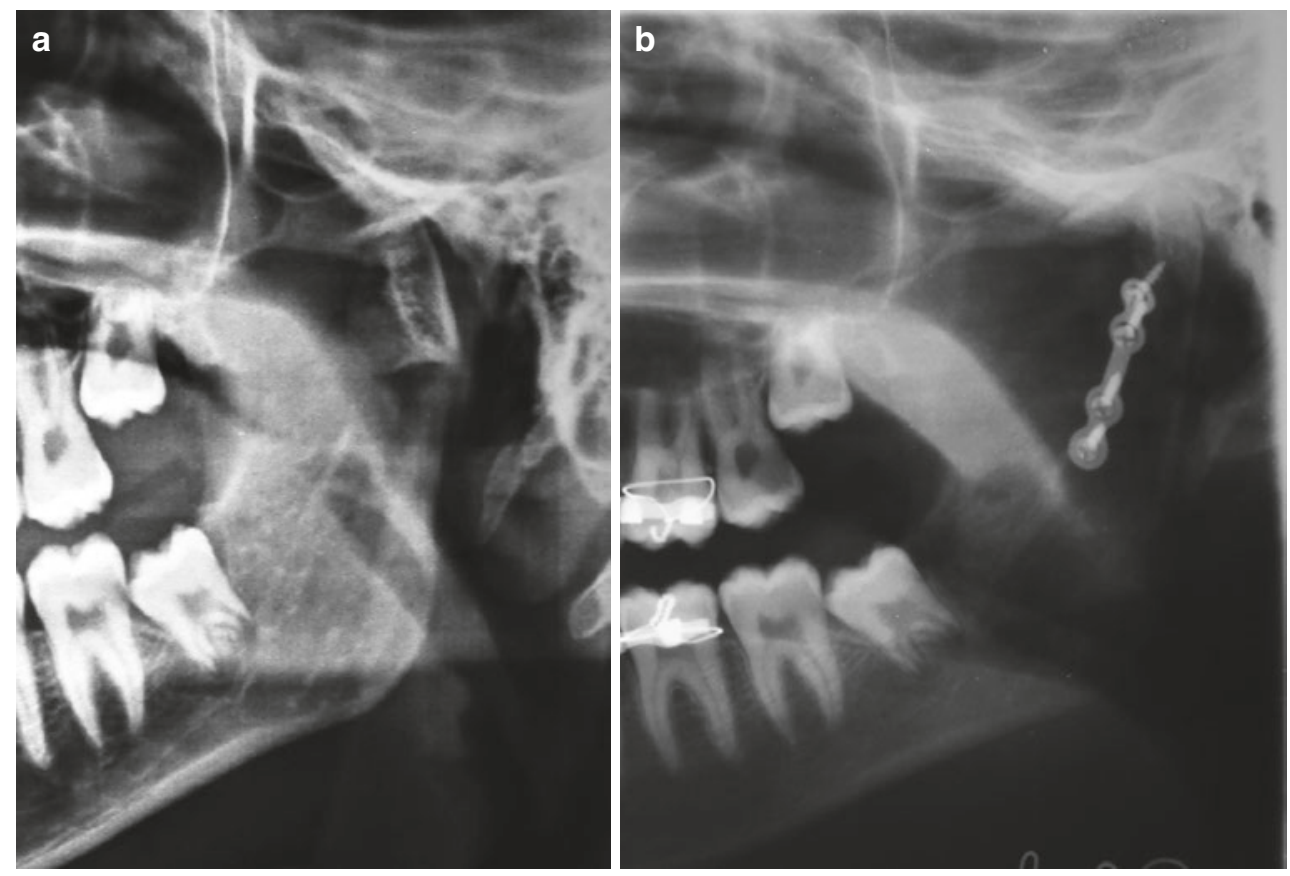

Case 1: Fig. 53.21 (a) OPG view showing left condyle fracture (b) Post operative OPG showing single plate fixed via retromandibular transparotid approach
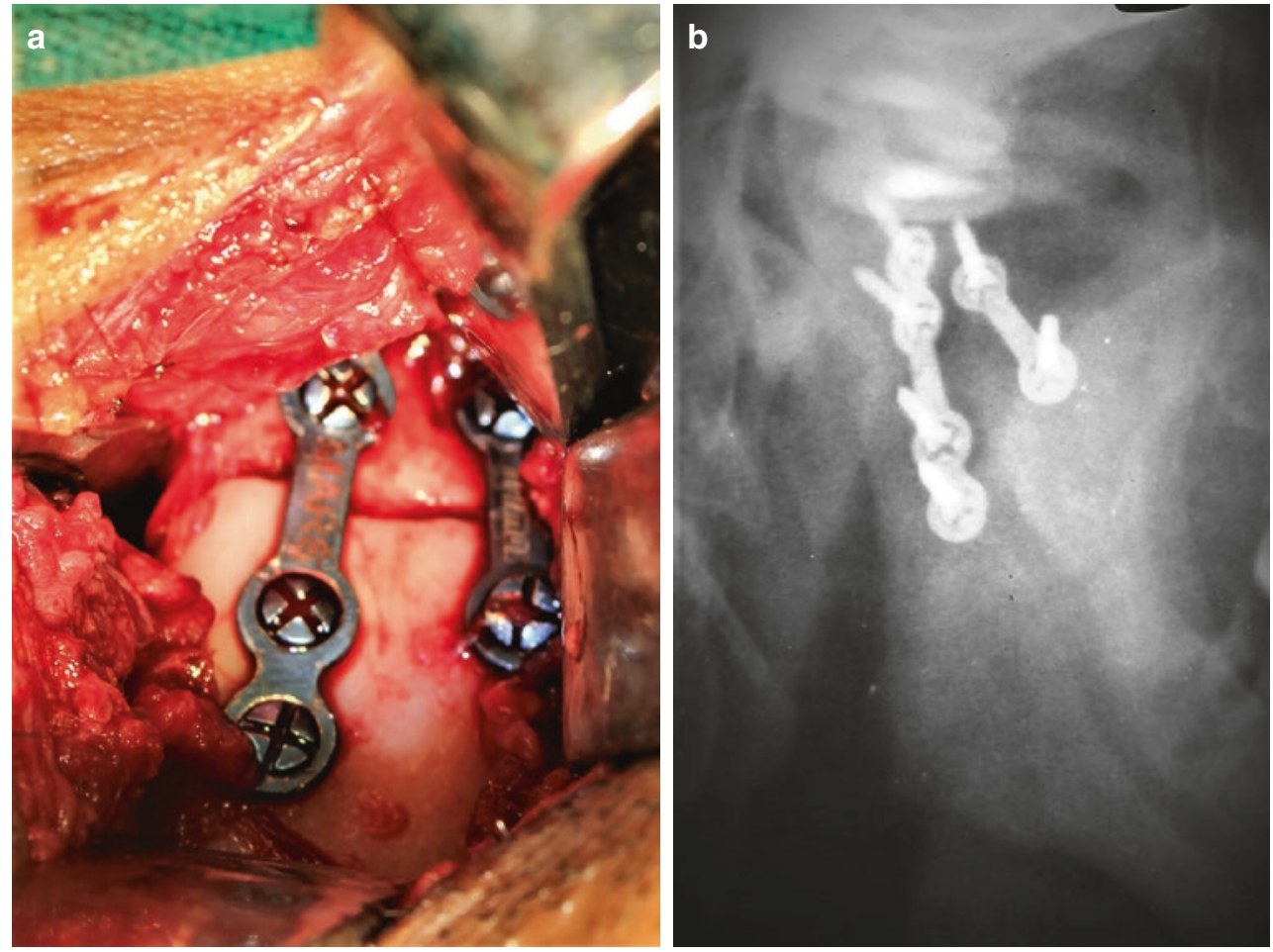

Case 2: Fig. 53.22 (a) Intra operative view showing two plates fixed for condyle fracture via retromandibular transparotid approach. (b) Post operative radiograph of showing fixation with two plates 

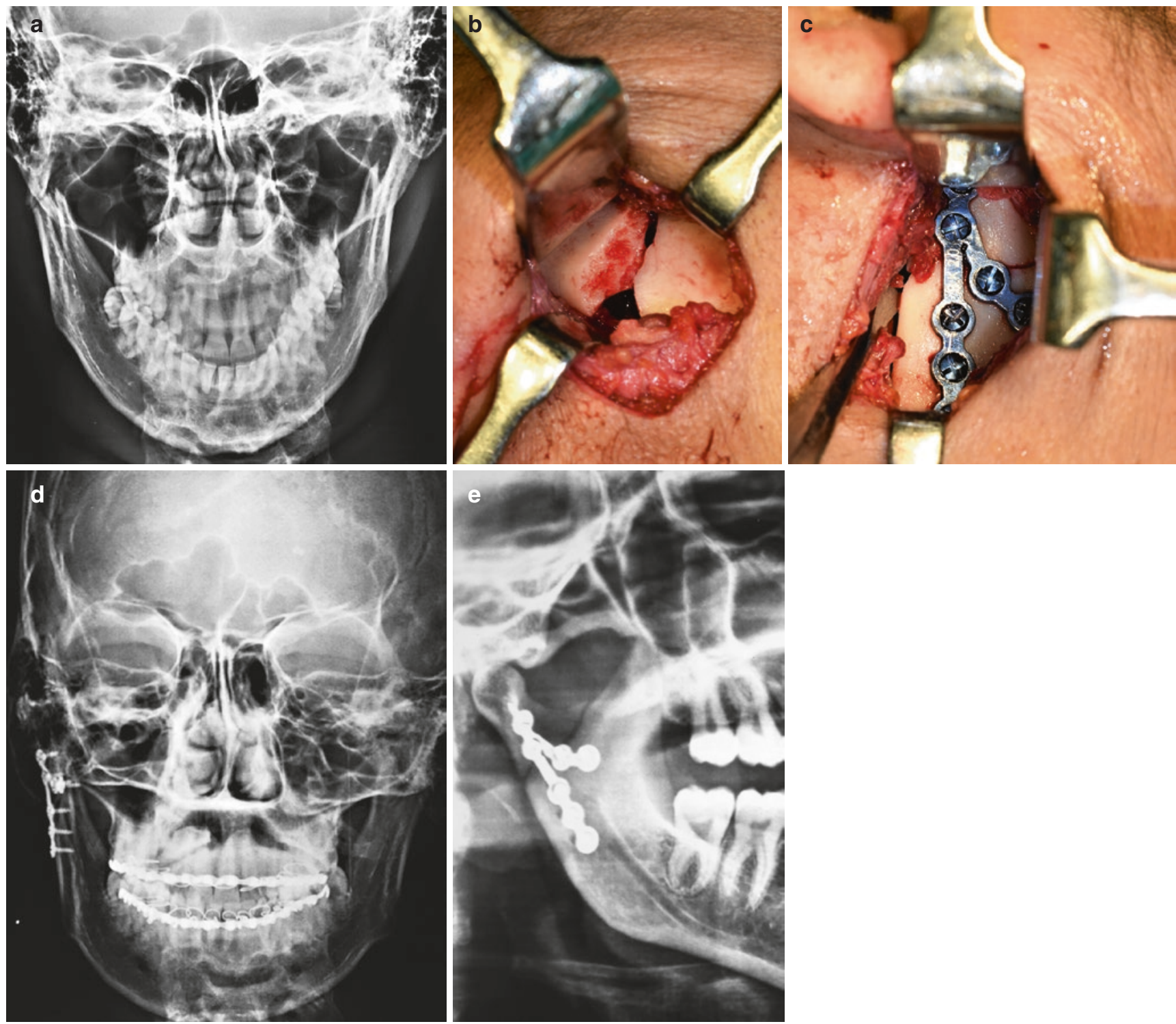

Case 3: Fig. 53.23 (a) PA view showing right condyle fracture. (b) Intraoperative view via retromandibular transparotid approach shows the displaced condyle. (c) Reduction and fixation done with Lambda plate. (d, e) Post operative PA view and OPG showing the fixed Lambda plates

\section{Box 53.10. Functional Exercise: Rehabilitation}

Targets [52]

1. Maximal mouth opening $>40 \mathrm{~mm}$

2. Lateral excursive movement $>10 \mathrm{~mm}$

3. Protrusive movement $>10 \mathrm{~mm}$

4. Full range of movements which are pain free

5. Close supervision by the surgeon

\subsection{Condylar Fractures in Children}

The most common fracture seen in the maxillofacial region in children is fracture of the condylar process [53]. Condyle is unique in children as there is a very thin cortical bone surrounding a highly vascular cancellous bone. This can result in a comminuted type of fracture also called mushrooming. Condylar fractures can result in definitive deformities, both in terms of function as well as 

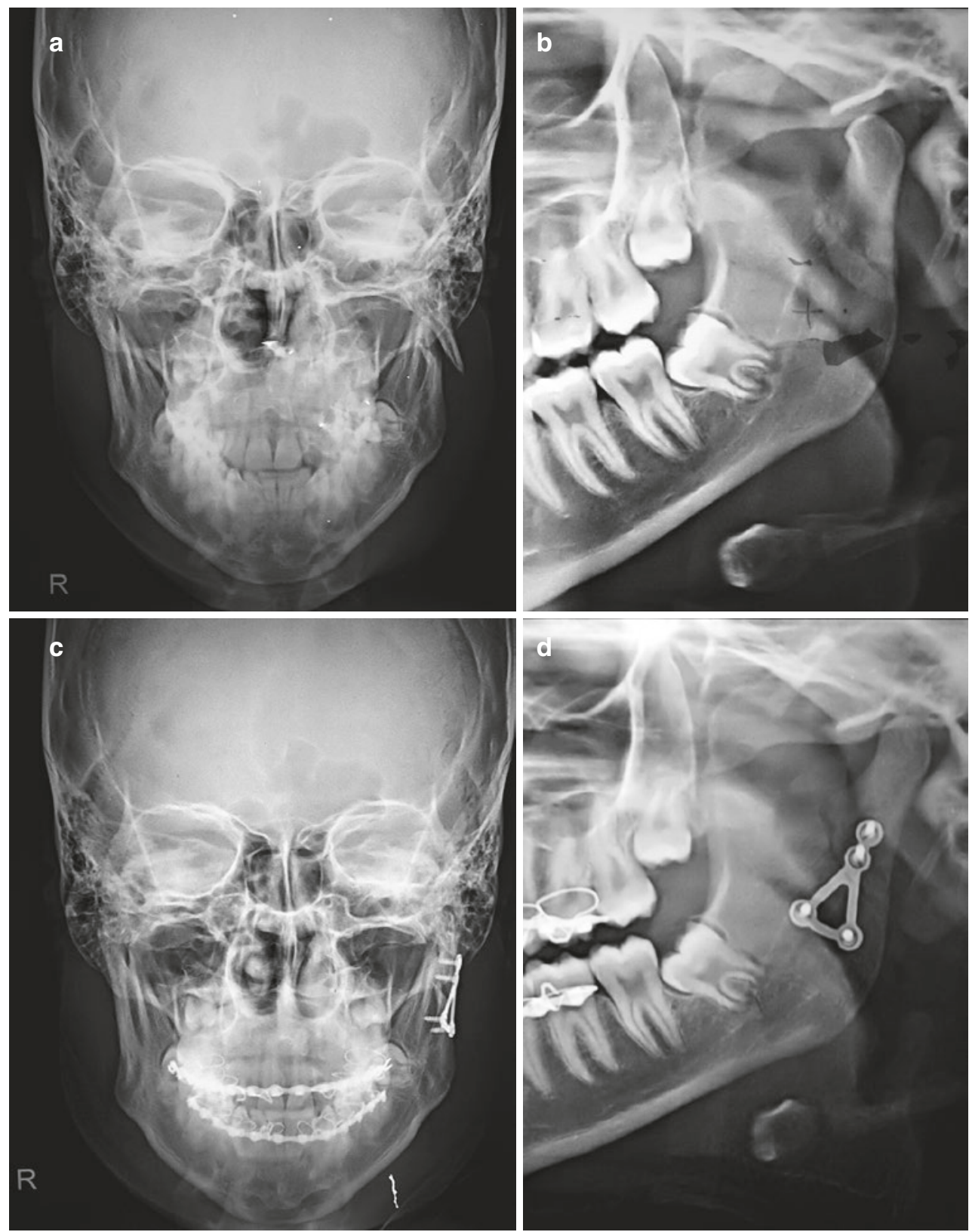

Case 4: Fig. 53.24 (a, b) Pre operative PA view and OPG showing fracture left condyle. (c, d) Post operative PA view and OPG showing the fixed Delta plate via Periangular approach

a facial asymmetry in cases of inappropriate treatment. Intracapsular fractures can result in retardation of growth $[54,55]$ or in excessive growth on the fractured site [56]. Remodelling of the condyle is inversely proportional to age $[9,25,26]$. Children have a better adaptation than the adults. Adaption in children is skeletal, neuromuscular, as well as function. In adults only functional adaptation is seen. For this reason, literature has supported conservative management of fracture of the condylar process. It is paramount to rehabilitate the patient with the restoration of minimum mouth opening, lateral excursion movement with stable occlusion. However, a long-term follow-up showed $50-53 \%$ of patients had complaints even though minor in nature irrespective of the type of treatment carried out [57]. Early mobilization is recommended in children below 15 years. Patients are encouraged to be on soft diet to avoid pain. In cases where an open bite is present, guiding elastics will help in restoring the occlusion. There is no concrete evidence of prolonged period of maxillomandibular fixation. 


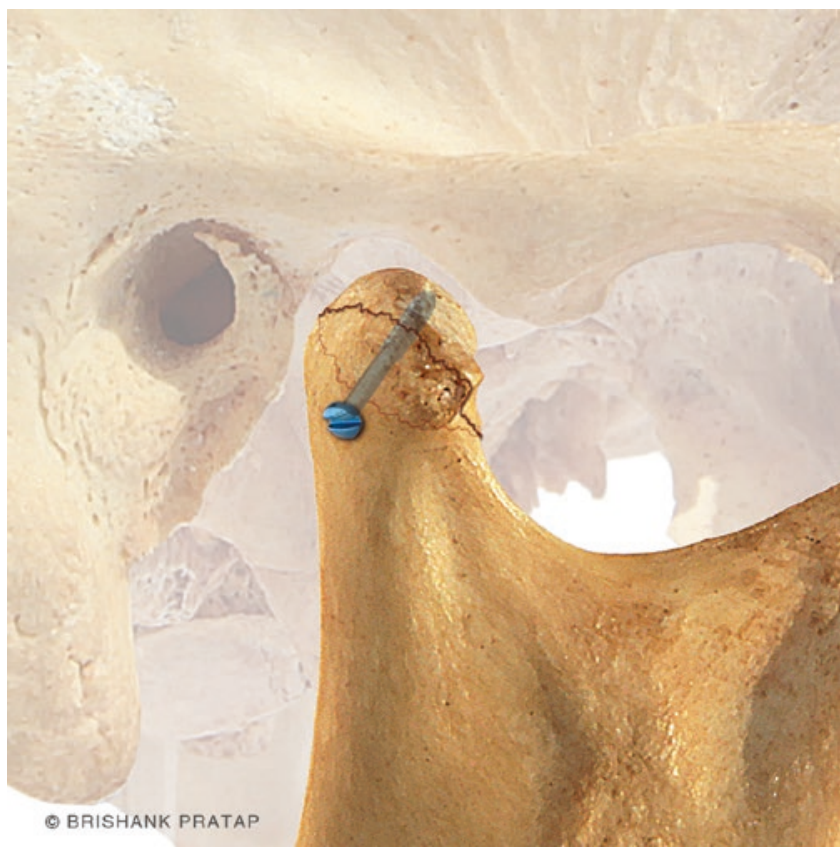

CAssociation of Oral and Maxillofacial Surgeons of India

Fig. 53.25 Fixation of the condylar head fracture with lag screw

Table 53.1 Comparison of different fixation methods used for fractures of the mandibular condyle

\begin{tabular}{|c|c|c|}
\hline $\begin{array}{l}\text { Type of plate } \\
\text { used for } \\
\text { fixation }\end{array}$ & Advantage & Disadvantage \\
\hline Single plate & $\begin{array}{l}\text { Easy to adapt and fix as } \\
\text { placed along the long axis } \\
\text { of the condyle. }\end{array}$ & $\begin{array}{l}\text { - Does not neutralize } \\
\text { the forces acting on } \\
\text { the fracture ends. } \\
\text { - Relatively heavier } \\
\text { plate needed. }\end{array}$ \\
\hline Two plates & $\begin{array}{l}\text { - Neutralizes the tension } \\
\text { and stress along the } \\
\text { fracture. } \\
\text { - Easy to triangulate. } \\
\text { - Aids in reduction of } \\
\text { fracture. } \\
\text { - Suitable with multiple } \\
\text { fractured fragments. }\end{array}$ & $\begin{array}{l}\text { - May be difficult to } \\
\text { fix two plates in a } \\
\text { narrow neck of the } \\
\text { condyle. }\end{array}$ \\
\hline $\begin{array}{l}\text { Lambda } \\
\text { plate }\end{array}$ & $\begin{array}{l}\text { - Single plate neutralizes } \\
\text { the tension and stress as } \\
\text { two lower limb follow the } \\
\text { anterior and posterior } \\
\text { border of the condyle. } \\
\text { - Suitable in narrow neck of } \\
\text { the condyle. }\end{array}$ & $\begin{array}{l}\text { - Wider exposure is } \\
\text { needed. } \\
\text { - Junction of two } \\
\text { lower and upper limb } \\
\text { area of weakness } \\
\text { prone for fracture. } \\
\text { - Difficult to adapt as } \\
\text { the stock plates may } \\
\text { not be suited for all } \\
\text { types of fractures. }\end{array}$ \\
\hline Delta plate & $\begin{array}{l}\text { - Single 3D plate } \\
\text { neutralizes the tension } \\
\text { and stress as two vertical } \\
\text { struts follow the anterior } \\
\text { and posterior border of } \\
\text { the condyle. } \\
\text { - Plates don't have an area } \\
\text { of weakness. }\end{array}$ & $\begin{array}{l}\text { - Wider exposure is } \\
\text { needed. } \\
\text { - Difficult to adapt. } \\
\text { - At times upper } \\
\text { horizontal strut may } \\
\text { be wider than the } \\
\text { bone available. }\end{array}$ \\
\hline
\end{tabular}

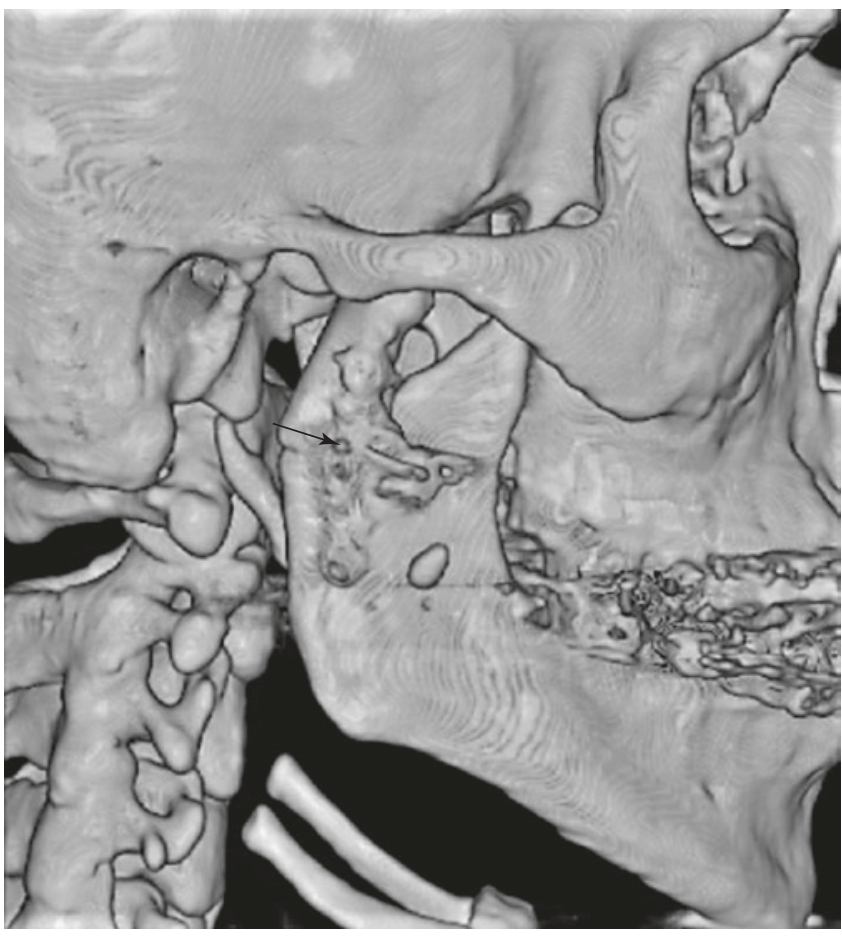

Case 5: Fig. 53.26 Shows improperly reduced fracture condyle which has been fixed in a dislocated position of the condyle-arrow points towards the plate fixed in wrong position

\subsection{Complications of Condylar Fractures (Case 5: Fig. 53.26) (Case 6: Fig. 53.27a-c)}

1. Malocclusion-Quite common with closed reduction if improperly treated. Also seen in patients with prolonged hospitalization [58].

2. Mandibular hypomobility-Prolonged immobilization and delayed physiotherapy, more common in children [59].

3. Ankylosis - seen more commonly in children due to meniscal disruption and lack of physiotherapy. This may be seen in comminuted fractures or disruption of articular disc.

4. Asymmetry-In children due to growth disturbances may result in facial asymmetry, occlusal cants, and reduced ramal height [60]. In adults asymmetry is due to deviation on opening of the mouth.

5. Dysfunctional degeneration-All injured joints can turn arthritic. Factors affecting these are age, long period of immobilization, capsular, or meniscal injury [61].

6. Condylar resorption-Occurs if the condyle becomes devoid of blood supply, but it is extremely rare.

7. Hardware failure-Such as fracture of plates can occur.

8. Infection-Postoperative infection.

9. Chronic pain seen in closed reduction.

10. Neurosensory disturbances-Seen following trauma or inappropriate surgical incisions. 

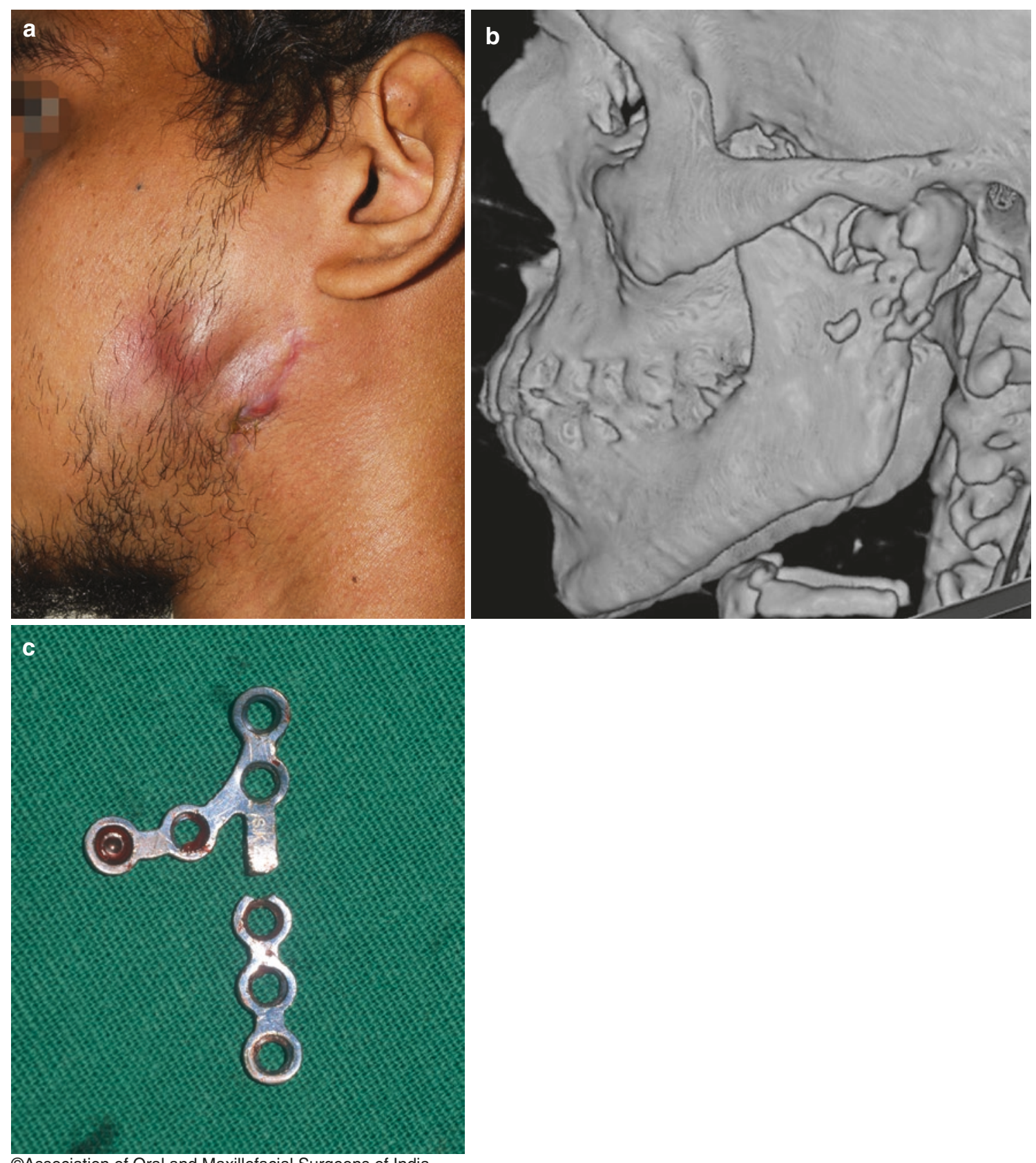

(CAssociation of Oral and Maxillofacial Surgeons of India

Case 6: Fig. 53.27 (a) Chronic infection left side condyle region following reduction and fixation, (b) CT scan showed osteomyelitis like changes at left condyle (c) the fractured infected plate removed 


\section{Box 53.11. Recent Advances [49]}

- Improvements in imaging (CT scan/MRI) have resulted in better visualization of fracture site and understanding of soft tissue injuries along with the fracture.

- Surgical approaches better understood, and their application is based on the site of condylar fracture.

- Importance of anatomic reduction which leads to early full range of function.

- Improvement in open or assisted internal fixation techniques.

- Ability to approach and manage intracapsular fractures.

- Need to manage soft tissue injury as and when need.

- There is an improvements and wide choice of fixation materials including resorbable materials.

- Early and effective postoperative rehabilitation.

\subsection{Conclusion}

There have been numerous controversies in management of condylar fractures. They have ranged from which classification to use, surgical approach, type of fixation, and outcome of the treatment. But till date even with all the advances available to us, we still cannot agree on the two schools of thought for management of condylar fracture that is closed or open. Danda et al. [38] concluded in their study that there was no difference in treatment outcome in both the groups. This can be debated as it is not possible to compare the two modalities of treatment in absolute terms. Although it is pointed out that there are better results in function with open reduction and fixation, there are inherent complications that are only seen in cases treated by open reduction [62] such as nerve injuries and scars.

In an alternative interpretation of evidence, Leon $\mathrm{A}$ Assael [63] opined that both open and closed reduction have a critical role in management of condylar fractures. Treatment outcome such as full pain free range of movement and good aesthetics is seen in both the groups. Malocclusion, functional deficit, and internal derangement are seen irrespective of line of treatment. Over the years, complications noted in open reduction have reduced with the better understanding and improvement of technique, but it can be burden on the patient. These complications can only be weighed against the functional advantage patient gets in open reduction and fixation. Treatment of a condylar fracture will entirely be dependent on multiple factors.
To conclude it can be safely stated that management of condylar fractures should be patient centric not entirely based on absolute indications mentioned by various authors. Generally, in children and dentulous adult patients, closed reduction is the choice of treatment, whereas open reduction and fixation would be the choice of treatment for the patients with multiple fractures of mandible, panfacial trauma, partially or totally edentulous jaws, and underlying medical conditions preventing maxillomandibular fixation. Finally, function should be considered as an important parameter while formulating a treatment plan along with the resources available and skill of the surgeon.

\section{References}

1. Desault BX. Memoire sur la fracture des condyles de la machoire inferieure. Paris: Euvres Chirurgicales; 1813.

2. Fletcher MC, Piecuch JF, Lieblich SE. Anatomy and pathophysiology of the temporomandibular joint. In: Milora M, Ghali GE, Larsen P, et al., editors. Peterson's principles of oral and maxillofacial surgery. 3rd edn. Shelton, CT: People's Medical Publishing House; 2012. p. 1033-47.

3. Rayne J. Functional anatomy of the temporomandibular joint. Br J Oral Maxillofac Surg. 1987;25:92-9.

4. Walker CJ, Stephen PR. MacLeod: anatomy and biomechanics of condylar fractures. Atlas Oral Maxillofacial Surg Clin N Am. 2017:25:11-6.

5. Schmidt BL, Pogrel MA. The distribution of the auriculotemporal nerve around the temporomandibular joint. Oral Surg Oral Med Oral Pathol Oral Radiol Endod. 1998;86:165-58.

6. Al-Kayat A, Bramley P. A modified pre auricular approach to the temporomandibular joint and malar arch. Br J Oral Surg. 1979;17:91-103.

7. Dingmann RO, Grabb WC. Surgical anatomy of the mandibular ramus of the facial nerve based on the dissection of 100 facial halves. Plast Reconstr Surg Transplant Bull. 1962;29:266-72.

8. Ellis E, Throckmorton GS. Treatment of mandibular condylar process fractures: biological considerations. J Oral Maxillofac Surg. 2005;63:115-34.

9. Lindahl L. Condylar fractures of the mandible. I: classification and relation to age, occlusion and concomitant injuries of the teeth and teeth-supporting structures and fractures of the mandibular body. Int J Oral Surg. 1977;6(1):12-21.

10. Chrcanovic BR. Surgical versus non-surgical treatment of mandibular condylar fractures: a meta-analysis. Int J Oral Maxillofac Surg. 2015;44(2):158-79.

11. Wassmund M. Frakturen und luxationen des gesichtsschädels unter berücksichtigung der komplikationen des hirnschädels. Ihre klinik, und therapie. Berlin: Meusser; 1927.

12. MacLennan WD. Consideration of 180 cases of typical fractures of the mandibular condylar process. Br J Plast Surg. 1952;5(2):122-8.

13. Spiessl, B., Schroll K. Spezielle Frakturen- und Luxationslehre. Ein kurzesHandbuch in fünf Bänden. Band I/1 Gesichtsschädel. Stuttgart: Georg Thieme; 1972. p. 317.

14. Rasse M. Diakapituläre frakturen der mandibula. Eine neue operationsmethode und erste ergebnisse. Stomatolgie. 1993;90:413-28.

15. Neff A, Kolk A, Deppe H, et al. Neue aspekte zur indikation der operativen versorgung intraartikulärer und hoher kiefergelenkluxationsfrakturen [New aspects for indications of surgical management of intra-articular and high temporomandibular dislocation fractures]. Mund Kiefer Gesichtschir. 1999;3(1):24-9. [in German] 
16. Hlawitschka M, Eckelt U. Assessment of patients treated for intracapsular fractures of the mandibular condyle by closed techniques. J Oral Maxillofac Surg. 2002;60(7):784-91.

17. Loukota R, Neff A, Rasse M. Nomenclature/classification of fractures of the mandibular condylar head. Br J Oral Maxillofac Surg. 2010;48(6):477-8.

18. He D, Yang C, Chen M, Jiang B, Wang B. Intracapsular condylar fracture of the mandible: our classification and open treatment experience. J Oral Maxillofac Surg. 2009;67(8):1672-9.

19. Loukota RA, Eckelt U, De Bont L, et al. Subclassification of fractures of the condylar process of the mandible. Br J Oral Maxillofac Surg. 2005;43:72-3.

20. Ellis E 3rd, Palmieri C, Throckmorton GS. Further displacement of condylar process fractures after closed treatment. J Oral Maxillofac Surg. 1999;59(2):120-9.

21. Neff A, Cornelius CP, Rasse M, et al. The comprehensive AOCMF classification system: condylar process fractures: level 3 tutorial. Craniomaxillofac Trauma Reconstr. 2014;7(Suppl 1):S44-58.

22. Brasileiro BF, Passeri LA. Epidemiological analysis of maxillofacial fractures in Brazil: A five-year prospective study. Oral Surg Oral Med Oral Pathol Oral Radiol Endod. 2006;102:28-34.

23. Chrcanovic BR, Freire-Maia B, Souza LN, et al. Facial fractures: A 1 year retrospective study in a hospital in Belo Horizonte. Braz Oral Res. 2004;18(1):322-8.

24. Kumar GBA, Dhupar V, Akkara F, Kumar SP. Patterns of maxillofacial fractures in Goa. J Maxillofac Oral Surg. 2013;14(2):138-14.

25. Ellis E, Moos KF, el-Attar A. Ten years of mandibular fractures: An analysis of 2,137 cases. Oral Surg Oral Med Oral Pathol. 1985;59(2):120-9.

26. Zachariades N, Mezitis M, Mourouzis C, et al. Fractures of the mandibular condyle: A review of 466 cases. Literature review, reflections on treatment and proposals. J Craniomaxillofac Surg. 2006;18:151-3.

27. MacLennan WD. Fractures of the mandibular condylar process. $\mathrm{Br}$ J Oral Surg. 1969;7:31-9.

28. Sawazaki R, Lima Júnior SM, Asprino L, Moreira RWF, de Moraes $\mathrm{M}$. Incidence and patterns of mandibular condyle fractures. J Oral Maxillofac Surg. 2010;68:1252-9.

29. Silvennoinen U, Iizuka T, Lindqvist C, et al. Different patterns of condylar fractures: An analysis of 382 patients in a 3-year period. J Oral Maxillofac Surg. 1992;50(10):1032-7.

30. Zachariades N, Koumoura F, Konsolaki-Agouridaki E. Facial trauma in women resulting from violence by men. J Oral Maxillofac Surg. 1990;48(12):1250-3.

31. Zachariades N, Papavassiliou D, Koumoura F. Fractures of the facial skeleton in children. J Cranio-Maxillofacial Surg. 1990;18(4):151-3.

32. Robert V. Walker: condylar fractures nonsurgical management. J Oral Maxillofac Surg. 1994;52:1185-8.

33. Zide MF, Kent JN. Indications for open reduction of mandibular condylar fractures. J Oral Maxillofac Surg. 1983;41(2):89-98.

34. AAOMS - special committee on parameter of care indications for open reduction of condylar fractures. https://www.researchgate. net/figure/AAOMS-special-committee-on-parameters-of-careindications-for-open-reduction-2003_tbl3_230633313. Accessed 1 Feb 2019.

35. Yates DM, Zuniga JR, Zide MF. Traumatic injuries to the mandibular condyle. In: Fonseca RJ, Walker RV, Dexter Barber H, Powers MP, Frost DE, editors. Oral \& maxillofacial trauma, 4th ed. 2012. p. 331-53.

36. Schneider M, Erasmus F, Gerlach KL, et al. Open reduction and internal fixation versus closed treatment and mandibulomaxillary fixation of fractures of the mandibular condylar process: A random- ized prospective, multicenter study with special evaluation of fracture level. J Oral Maxillofac Surg. 2008;66:2537-44.

37. Eckelt U, Schneider M, Erasmus F, et al. Open versus closed treatment of fractures of the mandibular condylar process-a prospective randomized multi-centre study. J Craniomaxillofac Surg. 2006;34:306-14.

38. Danda AK, Muthuskhar MR, Narayanan V, et al. Open versus closed treatment of unilateral subcondylar and condylar neck fractures: A prospective, randomized clinical study. J Oral Maxillofac Surg. 2010;68:1238-41.

39. Ellis E. Method to determine when open treatment of condylar process fractures is not necessary. J Oral Maxillofac Surg. 2009;67:1685-90.

40. Haug RH, Assael LA. Outcomes of open versus closed treatment of mandibular subcondylar fractures. J Oral Maxillofac Surg. 2001;59:370-5.

41. Silvennoinen U, Iizuka T, Oikarinen K, Lindqvist C. Analysis of possible factors leading to problems after nonsurgical treatment of condylar fractures. J Oral Maxillofac Surg. 1994;52:793-9.

42. Kent JN, Neary JP, Silvia C. Open reduction of mandibular condyle fractures. Oral Maxillofac Clin North Am. 1990;2:69-72.

43. Raveh J, Vuillenium T, Lädrach K. Open reduction of the dislocated, fractured condylar process: Indications and surgical procedures. J Oral Maxillofac Surg. 1989;47:120-6.

44. Pau M, Navisany K, Reinbacher K, et al. Use of a modified high submandibular approach to treat condylar base fractures: Experience with 44 consecutive cases treated in a single institution. J Craniomaxillofac Surg. 2016;44(10):164-45.

45. Trost O, Abu El-Naaj I, Trouilloud P, et al. High cervical transmasseteric anteroparotid approach for open reduction and internal fixation in condylar fracture. J Oral Maxillofac Surg. 2008;66:201.

46. Narayanan V, Ramadorai A, Ravi P, Nirvikalpa N. Transmasseteric anteriorparotid approach for condylar fractures: experience of 129 cases. Br J Oral Maxillofac Surg. 2012;50(5):420-4.

47. Ellis EE, Zide MF. Retromandibular approach. In: Ellis EE, Zide MF, editors. Surgical approaches to the facial skeleton. Baltimore, MD: Williams \& Wilkins; 1995. p. 139-53.

48. Cienfuegos R, Cornelius C-P, Ellis E III, Kushner G. Mandibleapproaches. In: Figari M, Sánchez Aniceto G, editors. Buchbinder $\mathrm{D}$ (general editor) AO surgery reference. https://www2.aofoundation.org $/ \mathrm{wps} / \mathrm{portal} /$ surgery?bone $=\mathrm{CMF} \&$ segment $=$ Mandible $\&$ sho wPage=approach. Assessed 1 Feb 2019.

49. Kisnisci R. Management of fractures of the condyle condylar neck, and coronoid process. Oral Maxillofacial Surg Clin N Am. 2013;25:573-90.

50. Devlin MF, Hislop WS, Carton AT. Open reduction and internal fixation of fractured mandibular condyles by a retro-mandibular approach: surgical morbidity and informed consent. Br J Oral Maxillofac Surg. 2002;40:23-5.

51. Vesnaver A. Open reduction and internal fixation of intra-articular fractures of the mandibular condyle: our first experiences. J Oral Maxillofac Surg. 2008;66(10):2123-9.

52. Palmieri C, Ellis E, Throckmorton G. Mandibular motion after closed and open treatment of unilateral mandibular condylar process fractures. J Oral Maxillofac Surg. 1999;57:764-75.

53. Lee CYS, McCullon C, Blaustein D, Mahammadi H. Sequelae of unrecognized, untreated mandibular condylar fractures in the pediatric patient. Ann Dent. 1993;52:5-8.

54. Posnick JC, Wells M, Pron GE. Pediatric facial fractures: Evolving patterns of treatment. J Oral Maxillofac Surg. 1993;51:836-4.

55. MacLennan WD, Simpson W. Treatment of fractured mandibular condylar process in children. Br J Plast Surg. 1965;18:423-7.

56. Lund K. Mandibular growth and remodelling processes after condylar fracture: A longitudinal roentgen cephalometric study. Acta Odont Scand. 1974;32:3-117. 
57. Levin SC, Frydendall E, Gao D, Chan KH. Temporomandibular joint dysfunction after mandibular fracture in children: A 10-year review. Arch Otolaryngol Head Neck Surg. 2011;137:10-4.

58. Ellis E 3rd. Complications of mandibular condyle fractures. Int J Oral Maxillofac Surg. 1998;27:255-7.

59. De Amaratunga NA. Mouth opening after release of maxillomandibular fixation in fracture patients. J Oral Maxillofac Surg. 1987;45:383-5.

60. Proffit WR, Vig KWL, Turvey TA. Early fracture of the mandibular condyles: Frequently an unsuspected cause of growth disturbances. Am J Orthod. 1980;78:1-24.
61. Palmieri C, Ellis E, Throckmorton G. Mandibular motion after closed and open treatment of unilateral mandibular condylar process fractures. J Oral Maxillofac Surg. 1999;57:764-75.

62. Brandt MT, Haug RH. Open versus closed reduction of adult mandibular condyle fractures: a review of the literature regarding the evolution of current thoughts on management. J Oral Maxillofac Surg. 2003;61:1324-32.

63. Assael LA. Open versus closed reduction of adult mandibular condyle fractures: an alternative interpretation of the evidence. J Oral Maxillofac Surg. 2003;61:1333-9.

Open Access This chapter is licensed under the terms of the Creative Commons Attribution 4.0 International License (http://creativecommons. org/licenses/by/4.0/), which permits use, sharing, adaptation, distribution and reproduction in any medium or format, as long as you give appropriate credit to the original author(s) and the source, provide a link to the Creative Commons license and indicate if changes were made.

The images or other third party material in this chapter are included in the chapter's Creative Commons license, unless indicated otherwise in a credit line to the material. If material is not included in the chapter's Creative Commons license and your intended use is not permitted by statutory regulation or exceeds the permitted use, you will need to obtain permission directly from the copyright holder. 